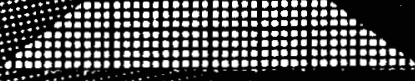

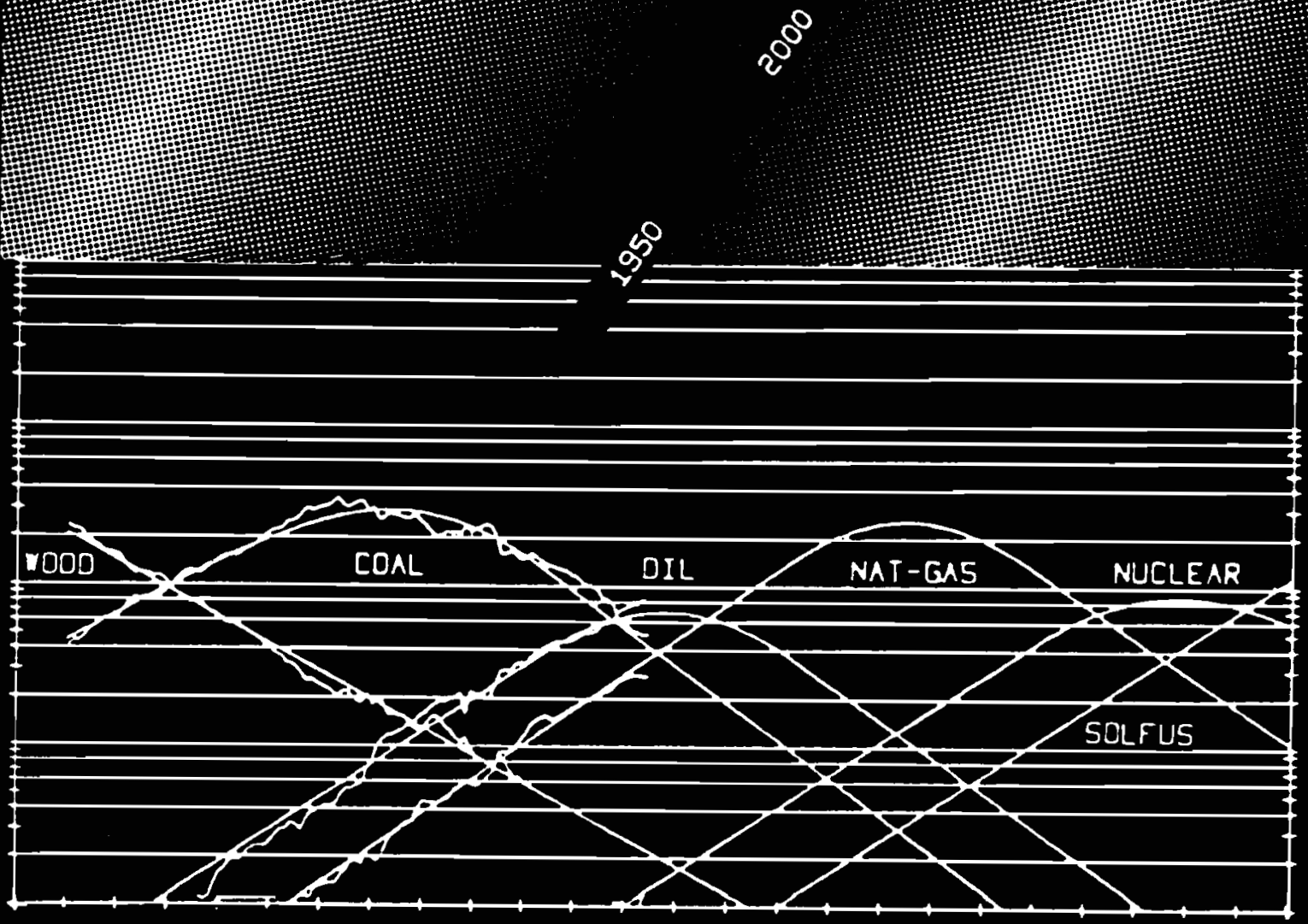

\title{
The Dynamics of
} Energy Systems and the Logistic Substitution Model

C. Marchetti

N. Nakicenovic

RR-79-13

DECEMBER 1979 


\section{THE DYNAMICS OF ENERGY SYSTEMS}

AND THE LOGISTIC SUBSTITUTION MODEL

C. Marchetti and N. Nakicenovic

RR-79-13

December 1979

Work carried out under a grant

from the Volkswagenwerk Foundation

INTERNATIONAL INSTITUTE FOR APPLIED SYSTEMS ANALYSIS

Laxenburg, Austria 



\section{PREFACE}

One of the objectives of IIASA's Energy Systems Program is to improve the methodology of medium- and long-range forecasting in the areas of the energy market and energy use, demands, supply opportunities and constraints. This is commonly accomplished with models that capture and put into equations the numerous relationships and feedbacks characterizing the operation of an economic system or parts of it. Such an approach encounters many difficulties, which are linked to the extreme complexity of the system and the fairly short-term variation of the parameters and even of the equations used. Consequently, these models lend themselves to short- and perhaps medium-range predictions, but normally fail to be useful for predictions over a period of about 50 years, the time horizon that the Energy Systems Program has chosen for study.

Following the current scheme of attacking similar problems in the physical sciences, we have left aside all details and interactions, and have attempted a macroscopic description of the system via the discovery of long-term invariants. Heuristically, this approach is certainly not new. In a broad sense, the sciences can be seen as a systematic search for invariants.

This work is dedicated to the empirical testing and theoretical formulation of an invariant, the logistic learning curve, as it applies to the structural evolution of energy systems and systems related to energy, such as coal mining. The great success of the model in organizing past data, and the insensitivity to major political and economic perturbations of the structures obtained seem to lend great predictive power to this invariant.

This Research Report represents only part of the work done at the International Institute for Applied Systems Analysis, under a grant from the Volkswagenwerk Foundation, FRG, on the potential of logistic 
analysis in describing energy systems. It is completely documented in the Administrative Report to the foundation entitled "The Dynamics of Energy Systems and the Logistic Substitution Model" (Marchetti et al. 1978).

The present paper reproduces the descriptive part in Section B of the Administrative Report. The software is described by Nakicenovic (1979). As for the theoretical treatment in Section C by Peterka, a new issue of "Macrodynamics of Technological Change: Market Penetration by New Technologies" is available (Peterka 1977). Fleck's contribution to Section C on the regularity of market penetration is part of his forthcoming doctoral dissertation at the University of Karlsruhe. Section A of the Administrative Report is the executive summary. 


\section{SUMMARY}

Information, material, and energy are the basic constituents of civilization, and it is most natural that we should try to assess their respective roles and internal mechanisms. The question of energy has been enjoying much attention lately, partly because of the very successful move by the oil cartel in 1973. The political consequences and the promotional infrastructure of that move have generated a highly emotional atmosphere, inimical to an objective appreciation of the facts. In this study in IIASA's Energy Systems Program, we have attempted to leave aside emotions and ad hoc interpretations. Sticking only to the facts, we have tried to find out if they have an internal order of their own, or, in the terminology of physics, if they can be described phenomenologically. We find that this is possible.

Our initial working hypothesis was that primary energies, such as wood, coal, oil, gas, and nuclear energy, are just technologies competing for a market. Consequently, market penetration analysis, as it has been developed by Mansfield (1961) and many others, should be applicable. In order to test the power and the limits of this analysis, we worked on as many examples as could be used, on three different levels of aggregation:

Primary energy inputs for the world as a whole

Primary energy inputs for individual nations or clusters of nations

Energy subsystems, such as electric utilities

$A$ total of about 300 cases were examined. Since the goodness of fit was consistently high, the examples in this report have been chosen for mainly didactic reasons. The United States is particularly well represented, largely because of the quality and detail of U.S. statistics. A good repre- 
sentation of FRG data was also attempted. Since supertankers have made the energy system a world system, the case of the world as a whole was given special attention for its political and resource implications. Although the main thrust of our analysis has been to provide a simple, objective, and internally consistent description of the past, we made a projection of the future, as it is described by the equations, and commented on it. But given that our projections are often different from what one has come to expect according to current wisdom, our attempt has to be considered exploratory. After all, it is perfectly legitimate in scientific research to test the limits of a newly discovered tool by extending its range of application beyond its "natural" bounds.

There is another important point to be mentioned, regarding possible control of the process of substitution of one technology for another. No technology can start from zero without external financial help. The magnitude of the initial external investment determines the initial conditions for the substitution, and may considerably accelerate the substitution process (or delay it, if the investment is too small), especially if the new technology is profitable but requires high investments. The example of nuclear energy is treated in some detail.

On the whole, we believe that the basic objective of this work has been fulfilled: we explored the field experimentally, showing the great efficiency of our model in organizing data. In doing so, we have presumably generated more problems than we have solved, which is a good indication that we have been plowing a fertile field. 


\section{CONTENTS}

1 Introduction 1

2 The Logistic Function and Substitution Dynamics 1

3 A Simplified Analytical Treatment 5

4 Comments and Warnings on Using the Charts for Prediction 6

5 The Examples 8

The World $\quad 10$

Federal Republic of Germany $\quad 22$

France $\quad 32$

United Kingdom $\quad 36$

United States $\quad 38$

Organisation for Economic Co-operation and Development (OECD):

Europe $\quad 56$

Austria $\quad 58$

Belgium $\quad 60$

The Netherlands $\quad 62$

France $\quad 64$

United Kingdom $\quad 65$

Italy $\quad 66$

$\begin{array}{ll}\text { Canada } & 67\end{array}$

Japan $\quad 68$

Data Sources $\quad 70$

References $\quad 71$

vii 



\section{INTRODUCTION}

Four years ago, the International Institute for Applied Systems Analysis began a study of energy systems using the techniques of market penetration analysis. The basic hypothesis - which has proved very fruitful and powerful - is that primary energies, secondary energies, and energy distribution systems are just different technologies competing for a market and should behave accordingly.

Previous analysis of market competition had always been performed for only two competitors. But it is a peculiarity of energy systems over the last hundred years that most of the time more than two competitors took important shares of the market. Thus, we had to modify the original rules by introducing new constraints that permitted us to deal with more complicated cases. These constraints were defined empirically from a few cases, but proved very successful in dealing with virtually all the cases that we analyzed. A mathematical formulation of the substitution process is given below and the manual for the software package is given in Nakicenovic (1979).

\section{THE LOGISTIC FUNCTION AND SUBSTITUTION DYNAMICS}

Substitution of a new way for the old way of satisfying a given need has been the subject of a large number of studies. One general finding is that almost all binary substitution processes, expressed in fractional terms, follow characteristic S-shaped curves, which have been used for forecasting further competition between the two alternative technologies or products, and also the final takeover by the new competitor. 
Most of the studies of technological substitution are based on the use of the logistic function. The logistic function, however, is not the only S-shaped function, but it is perhaps the most suitable one for empirical analysis of growth and substitution processes because of both the ease in interpreting the meaning of its parameters and the simplicity in estimating the parameters from the observed phenomena. Another S-shaped function, the Compertz curve, has also been frequently used, especially to describe population, plant, and animal growth (see, e.g., Richards 1959).

The widespread empirical applications of the logistic function as a means of describing growth phenomena also originated in the studies of human population, biology, and chemistry. The first reference to the logistic function can be found in Verhulst $(1838,1845,1847)$. Pearl $(1924,1925)$ rediscovered the function and used it extensively to describe the growth of populations, including human population. From then on, numerous studies have been conducted only to confirm the logistic property of most growth processes. Robertson (1923) was the first to use the function to describe the growth process in a single organism or individual. Later, the function found application in work concerning bioassays (see e.g., Emmens 1941, Wilson and Worcester 1942, and Bergson 1944), and in work on the growth of bacterial cultures in a feeding solution, autocatalyzed chemical reactions, and so on.

One of the first studies that showed that technological substitution can be described by an S-shaped curve was the pioneering work of Griliches (1957) on the diffusion of the hybrid corn seed in the United States. He showed that hybrid corn replaced traditional corn seed in different states in a very similar way; the S-shaped substitution was only displaced in time by a few years and lasted differing lengths of time from one state to another.

Following the work of Griliches, Mansfield (1961) developed a model to explain the rate at which firms follow an innovator. He hypothesized that the adoption of an innovation is positively related to the profitability of employing the innovation and negatively related to the expected investments associated with this introduction. Mansfield substantiated the theoretical implications of his model by the empirical analysis of the diffusion of 12 industrial innovations in four major industries.

One of the most notable models of binary technological substitution, which extended Mansfield's findings, was formulated by Fisher and Pry (1970). This model uses the two-parameter logistic function to describe the substitution process. The basic assumption postulated by Fisher and Pry is that once a substitution of the new for the old has progressed as far as a few percent, it will proceed to completion along a logistic substitution curve: 


$$
\frac{f}{1-f}=\exp (\alpha t+\beta)
$$

where $t$ is the independent variable usually representing some unit of time, $\alpha$ and $\beta$ are constants, $f$ is the fractional market share of the new competitor, and $1-f$ that of the old one. The coefficients $\alpha$ and $\beta$ are sufficient to describe the whole substitution process. They cannot be directly observed; they can, however, be estimated from the historical data.

Two sets of examples are shown here (Figures 1 and 2) from the original papers of Fisher and Pry (Fisher and Pry 1970, Pry 1973). The logistic functions appear to give an excellent description of substitution, not only for very different products and technologies, but also for different types of economies.

In dealing with more than two competing technologies, we have had to generalize the Fisher-Pry model since in such cases logistic substitution

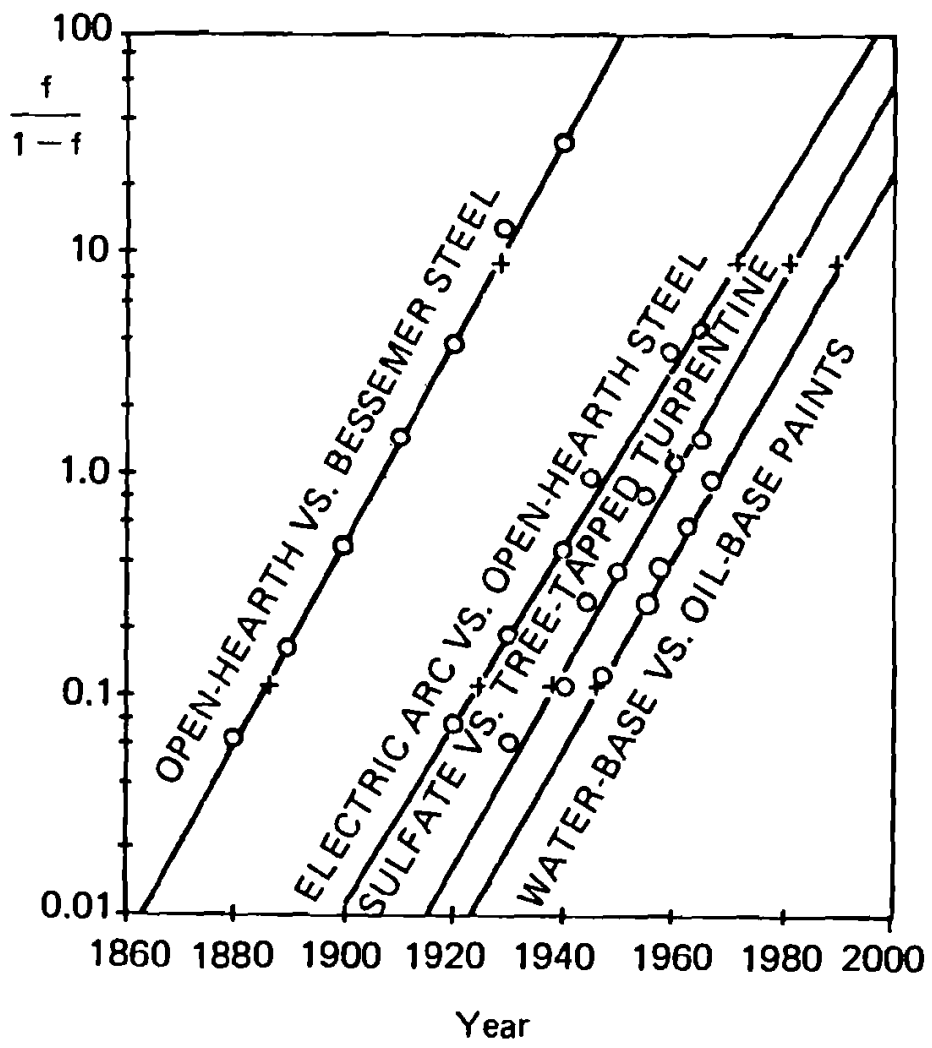

FIGURE 1 Technological substitution in the production of steel, turpentine, and paints. Source: Fisher and Pry (1970). 


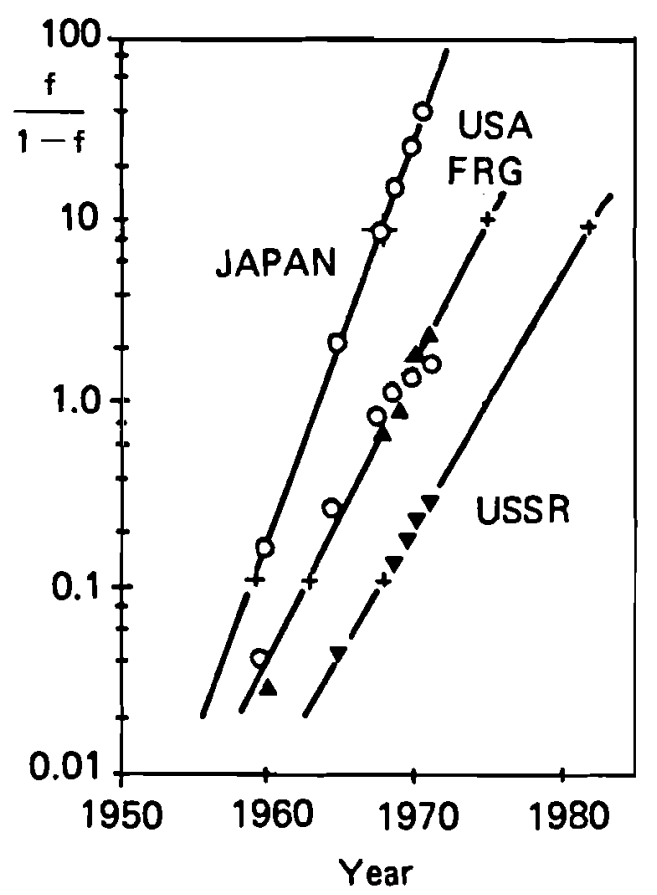

FIGURE 2 Substitution of the basic oxygen furnace for open-hearth and Bessemer steel production. On the line in the middle, the triangles represent the FRG and the circles represent the USA. Source: Pry (1973).

cannot be preserved in all phases of the substitution process. Every given technology undergoes three distinct substitution phases: growth, saturation, and decline. The growth phase is similar to the Fisher-Pry binary logistic substitution, but it usually terminates before full substitution is reached. It is followed by the saturation phase which is not logistic, but which encompasses the slowing of growth and the beginning of decline. After the saturation phase of a technology, its market share proceeds to decline logistically.

We assume that only one technology is in the saturation phase at any given time, that declining technologies fade away steadily at logistic rates uninfluenced by competition from new technologies, and that new technologies enter the market and grow at logistic rates. The current saturating technology is then left with the residual market share and is forced to follow a nonlogistic path that joins its period of grow th to its subsequent period of decline. After the current saturating technology has reached a logistic rate of decline, the next oldest technology enters its saturation 
phase and the process is repeated until all but the most recent technology are in decline. In effect, our model assumes that technologies that have already entered their period of market phaseout are not influenced by the introduction of new ones. Deadly competition exists between the saturating technology and all other technologies.

\section{A SIMPLIFIED ANALYTICAL TREATMENT}

Let us assume that there are $n$ competing technologies ordered chronologically in the sequence of their appearance in the market, technology 1 being the oldest and technology $n$ the youngest. Over a certain historical interval we estimate the coefficients of the logistic functions for the technologies in the logistic substitution phases. Typical historical periods we have investigated range from 130 to 20 years. The substitution process can be simulated, however, over any desired time interval which need not overlap with the historical period. Let us call the beginning of this interval $t_{\mathrm{B}}$ and the end $t_{\mathrm{E}}$.

After the coefficients have been estimated, either by ordinary least squares or by some other method, we have $n$ equations:

$$
f_{i}(t)=1 /\left[1+\exp \left(-\alpha_{i} t-\beta_{i}\right)\right]
$$

where $i=1, \ldots, n$ and where $\alpha_{i}$ and $\beta_{i}$ are the estimated coefficients. Now we identify the saturating technology, $j$, as the oldest technology still increasing its market share. The market shares are then defined by:

$$
f_{i}(t)=1 /\left[1+\exp \left(-\alpha_{i} t-\beta_{i}\right)\right] \quad \text { for } i \neq j
$$

For $j$ they are defined by

$$
f_{i}(t)=1-\sum_{i \neq j} f_{i}(t)
$$

At this time, technology $j$ is in its saturation phase and all other technologies are either growing or declining logistically.

Now we need a criterion to identify the end of the saturation phase and the beginning of the decline of technology $j$, at which time the function $f_{j}(t)$ will become logistic again on its way down and the burdens of saturation will fall on technology $j+1$. To establish this criterion, we use the properties of the function

$$
y_{j}(t)=\log \frac{f_{j}(t)}{1-f_{j}(t)}
$$


If $f_{j}(t)$ were logistic, $y_{j}(t)$ would be linear in $t$. However, for $f_{j}(t)$ in its saturation stage, the function $y_{i}(t)$ has negative curvature, passes through a maximum where technology $j$ has its greatest market penetration, and then decreases. The curvature diminishes for a time, indicating that $f_{j}(t)$ is approaching the logistic form, but then, unless technology $j$ is shifted into its period of decline, the curvature can begin to increase as newer technologies enter the market place. Phenomenological evidence from a number of substitutions suggests that the end of the saturation phase should be identified with the time when the ratio of the curvature of $y_{j}(t)$ to its slope reaches its minimum value. We take this criterion as the final constraint in our generalization of the substitution model, and from it we determine the parameters for technology $j$ in its logistic decline.

In mathematical form, the criterion for termination of the saturation phase for technology $j$ is

$$
y_{j}^{\prime \prime}(t) / y_{j}^{\prime}(t)=\text { minimum }
$$

(note that $y^{\prime \prime}$ and $y^{\prime}$ are both negative in the region of the minimum). When the minimum condition is satisfied, we call this time point $t_{j+1}$, the time of the beginning of saturation for technology $j+1$, and determine coefficients $\alpha$ and $\beta$ for the declining phase of technology $j$ from the relationships

$$
\begin{aligned}
& \alpha_{j}=y_{j}^{\prime}\left(t_{j+1}\right) \\
& \beta_{j}=y_{j}\left(t_{j+1}\right)-\alpha_{j} t_{j+1}
\end{aligned}
$$

Then the next-oldest technology $j+1$ enters its saturation phase, and the process is repeated until the last technology $n$ enters its saturation phase, or the end of the time period $t_{\mathrm{E}}$ is encountered.

These expressions determine the temporal relationships between the competing technologies. Only time $t$ and the estimated coefficients $\alpha_{i}$ and $\beta_{i}$ extracted from historical data have been treated as independent variables.

\section{COMMENTS AND WARNINGS ON USING THE CHARTS FOR PREDICTION}

Logistic analysis has shown an unexpected capacity to organize historical data, in that the information relevant to the evolutionary behavior of energy systems is contained in very restricted time series. This provides a very sound basis for using it for prediction. However, a certain number of precautions should be taken, or at least kept in mind when using the results. 
First of all, a new primary energy, like any new technology, is introduced first by drawing capital and resources from the industrial and economic environment. This "investment in faith" usually shows up with very fast rates of market penetration right at the beginning followed by a reflection period, after which speed is resumed in compliance with the market. As a new technology, now a new industry, has to walk on its own legs, its speed of penetration is always lower. This transition point, or kink in the curve, usually occurs by the time penetration has reached 2 or 3 percent of the market. If this kink does not show up, one is left with the suspicion that it will occur later, so that the final rate of penetration has to be guessed from other indicators. The most useful indicator is the time constant prevalent for other substitutions in the same system, and this is what we often use for our scenarios.

In the energy field, natural gas has the tendency to keep the boosted track up to even 10 percent of market penetration. This behavior merits further study as it may permit a better insight into the introduction period of a new technology. One of the possible explanations is that at the beginning, natural gas can fill an existing distribution infrastructure so that only trunk transportation has to be provided during the initial phase.

Secondly, the model does not predict the introduction of a new technology. This limits the time horizon of forecasting. Analysis of numerous cases has shown that each system has a fairly stable time constant. For example, the time constant (time to go from 1 to 50 percent of the market share) for the introduction of a new energy source in the world is about 100 years. Consequently, from the point of view of the competitors, not very much is going to happen during the first 50 years of the introduction of a new technology. This offers much breathing space when we discuss the world. But prudence is advisable when we deal with a time constant of only 20 or 30 years, as we find for the FRG.

The weakest point for the predictions over the next 50 years is the role of nuclear energy; we have a starting point for the curve, but we still cannot determine the slope. For that reason, we intentionally took prudent values, e.g., a penetration of only 6 percent for the world in the year 2000 , backed by a slightly more optimistic value of 10 percent. At these levels of nuclear energy penetration, it is clear that the predictions of the future roles of the various sources of energy based on this model contradict most of the predictions in the current literature, which are mainly controlled by the much looser constraints of resource availability and political opportunity.

The causal importance of resource availability is weakened by the 
fact that oil successfully penetrated the energy market when coal still had an enormous potential, just as coal had previously penetrated the market when wood still had an enormous potential. The causal importance of the political argument is weakened by the smooth substitution observed over a period of more than a century, when political moods changed quite frequently and drastically. Furthermore, the drastic changes in energy prices after 1973, even if of monopolistic origin, do not appear a sufficient cause to change the rates of substitution; similar price changes in the past did not affect them either. This has been so at least for the medium- and longrun, presumably because of rapid relative price re-adjustments between various energy sources. While this is only a hypothesis, which merits a deeper study, the very rapid price adjustments after recent oil price increases are well in tune with it.

The most important predictions of our model that differ from those in the current literature are that there will be

A relatively rapid phaseout of coal as a primary energy source A quite important role for natural gas in the next 50 years

A negligible role in the next 50 years for new sources such as geothermal energy, solar energy, and fusion because of the very long lead times intrinsic to the system

The curious fact about the last point is that the flourish of very expensive research on these sources implies a fairly low discounting factor in decisions on the allocation of funds for energy R\&D. This appears to be very wise, if not internally consistent, because the lead times of the systems are so long that nothing could be started rationally if higher discounting rates were used.

These and many other predictions (like the compatibility of resources with demand), although extremely interesting, are not really part of our research task; our work is centered in the past, where we try to find order and which we try to understand rationally.

\section{THE EXAMPLES}

The aim of the experimental part is to show the scope and power of the method by taking as many examples as possible from three different levels of aggregation:

Primary energy inputs for the world as a whole

Primary energy inputs for single nations or a cluster of nations

Energy subsystems, such as electric utilities 
In total, we used 60 data bases to generate 300 examples for 30 different spatial and structural subsets of the world energy system. The goodness of fit was consistently high in all examples, so the cases reported here have been chosen mainly for didactic reasons.

The United States is particularly well represented, largely because of the quality and detail of its statistics. We also made an effort to have a good representation for the Federal Republic of Germany. If this research should be continued, collaboration with an institute for statistics would have a multiplicative effect on the results.

To make the curves easy to interpret, the substitution graphs are drawn using the transformation $\log [f /(1-f)]$ versus time ( $f$ being the market share). This makes the top and bottom part of the graph very sensitive and this fact should be kept in mind when drawing conclusions only from an examination of the graphs. The graphs showing total energy consumption are drawn on either logarithmic or linear axes, or on both, depending on the dispersion of the data. 
VDRL - PRIUARY ENERTY CONSUMPTION

BIL. TCE

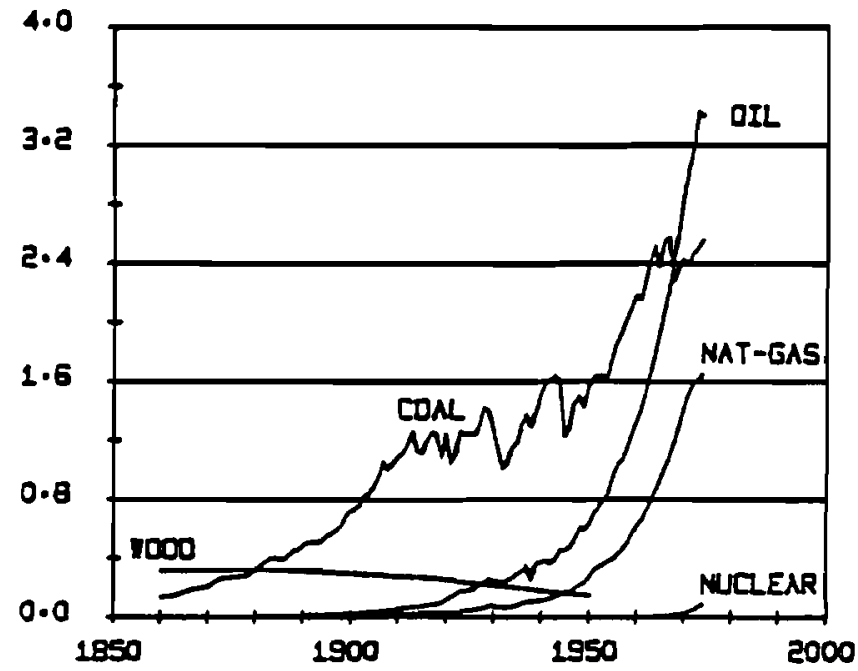

World energy consumption is reported first in various forms to illustrate and clarify our methods of logistic analysis. Our world statistical data base includes wood, coal, oil, natural gas, and nuclear energy as the major energy sources of history.

Historical data on the consumption of coal, oil, natural gas, and nuclear energy from 1860 to 1974 were taken from Schilling and Hildebrandt (1977), and data on fuel wood consumption were taken from Putnam (1953). Although fuel wood consumption levels for the years 1950 to 1974 were not available, during this period the use of fuel wood was not very large so that any error thus introduced is not significant. All energy sources have been expressed in terms of their energy content in tons of coal equivalent (tce); 1 tce equals 7 million kcal.

Nuclear energy was not available directly as primary equivalent but in gigawatt hours of electricity (GWh(e)). We have converted nuclear electric energy into tce of nuclear energy on the basis of an overall thermal-toelectric conversion rate of 33 percent.

The energy inputs for the world are plotted here in billions of tce according to primary energy form. Many features related to economic or political events appear in the figure, but no consistent patterns are visible. Initial growth of new sources appears to be exponential. The smoothness of the line for wood raises suspicion and points to artificial estimation methods used to generate the original wood consumption time series. 
VORLO - PRIUARY ENERGY CONSUMPTION

UILL. TCE

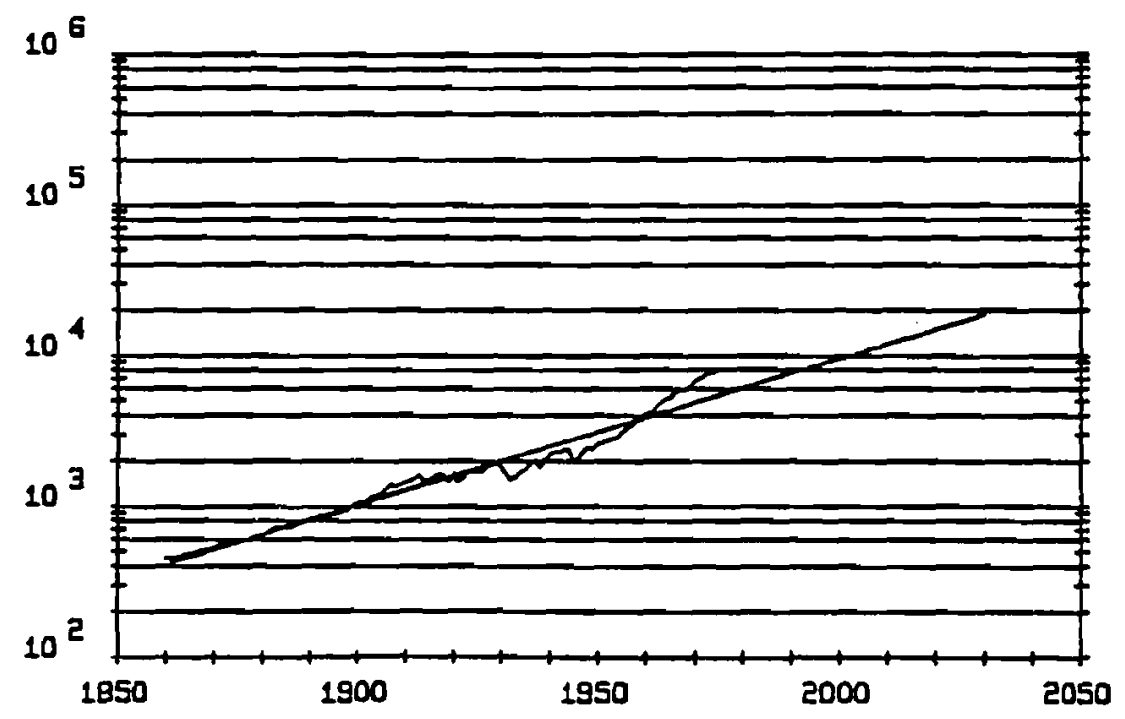

When wood is included with the commercial energy sources, the development of world energy consumption appears fairly regular until World War II, with a growth of 2.2 percent per year. After 1950 , not only were the losses reabsorbed that occurred as a consequence of the great recession, but some overshooting occurred with respect to the trend line. This may have been caused by an increase in the rate of population growth after the war. The increase in energy costs may well temper this rate again. 
TORL - PRIMARY ENERGY CONSUMPTION

9II. TEE

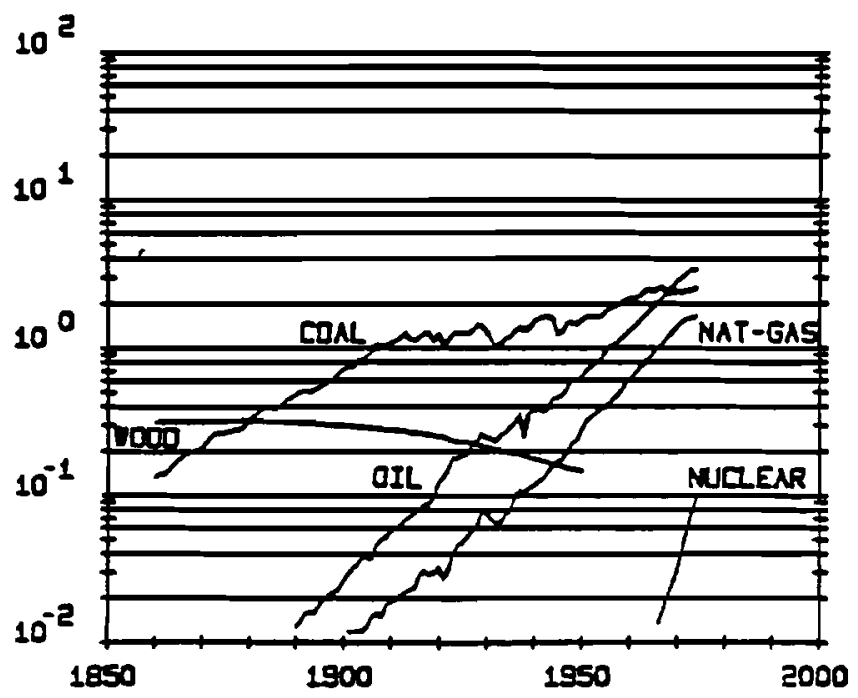

New sources appear to grow with exponential trends. Therefore, we plotted them in semilogarithmic form. The presence of some straight lines indicates that we are moving in the right direction, but we still do not find consistent general trends allowing a precise mathematical description of the evolution of the use of the various primary energy sources. 
WORL - PRIUARY ENIRGY SUASTITUTION

\section{FRACTION (F)}

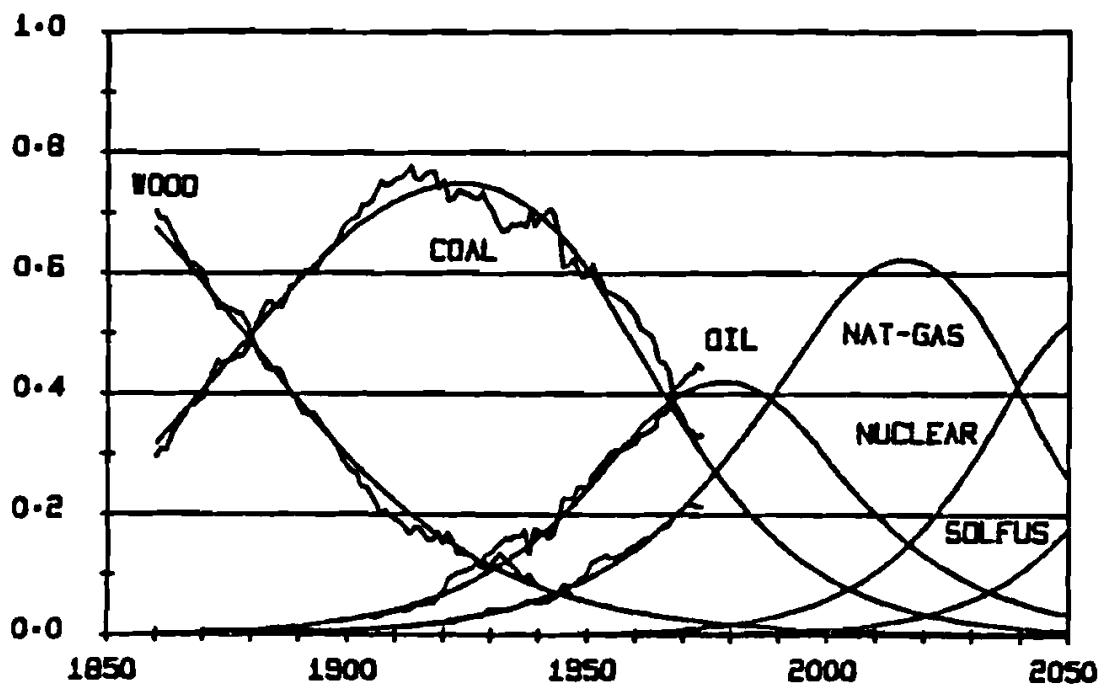

Here the contributions of the various primary sources are shown as fractions of the total market. The smooth curves are two-parameter logistics assembled in a system of equations as described in the text. The fitting appears perfect for historical data.

When we look to the future, the figure contains two primary energy sources for which a complete fitting of the parameters was not possible. For nuclear energy the present penetration is still too low to determine the slope of the penetration. We have estimated the rate from progress to date and from official plans. For SOLar or FUSion, the scenario is completely hypothetical. Because rates of penetration were almost the same for coal, oil, and gas, we assumed an equal rate for nuclear and SOLFUS, in the spirit of "business as usual." The unexpected dominance of natural gas over the next 50 years will be discussed later in the report. 
VDRLD - PRIUARY ENERGY SUBSTITUTION

$$
F /(1-F)
$$

FRACTION (F)

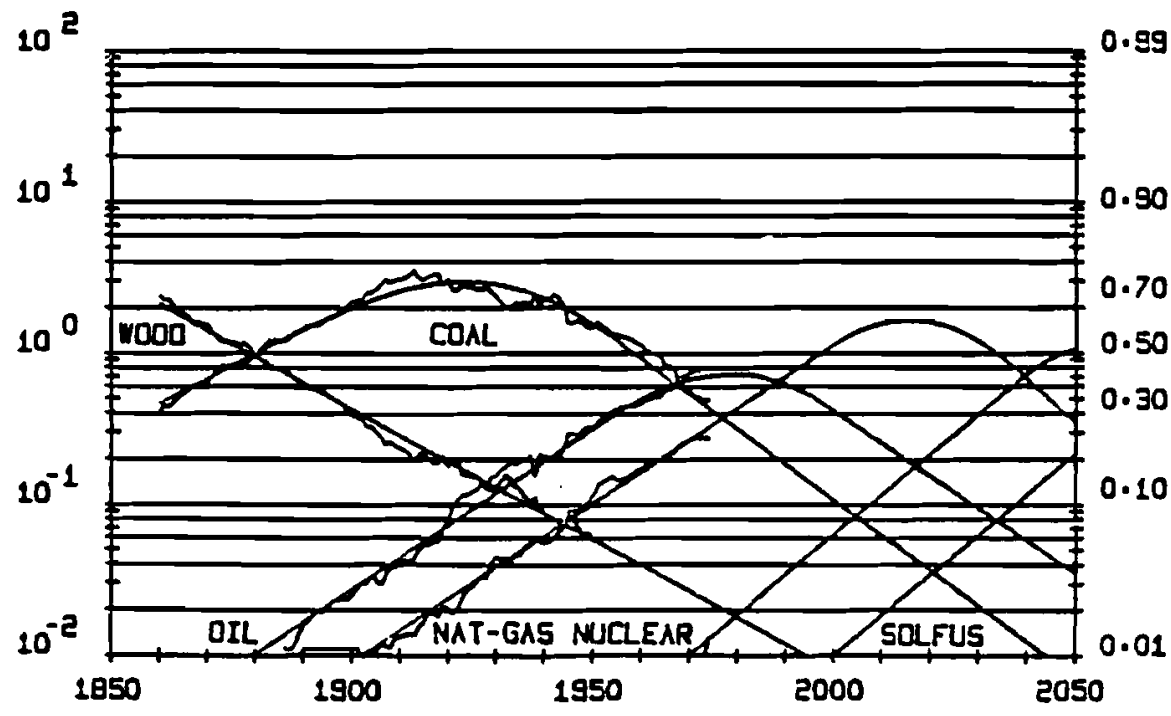


The curves of the preceding figure are now plotted as $\log [f /(1-f)]$; the logistic curves appear as straight lines, greatly helping visual inspection and formal considerations. The first fact to be observed is the extreme regularity and slowness of the substitution. It takes about 100 years to go from 1 percent to 50 percent of the market. We call this length of time the time constant of the system.

The regularity refers not only to the fact that the rate of penetration (defined as constant $\alpha$ in the equation and corresponding to the slope of the curves) remains constant over such very long periods when so many perturbing processes seem to take place, but also to the fact that all perturbations are reabsorbed elastically without influencing the trend. It is as though the system had a schedule, a will, and a clock.

It is also interesting to note that no source finally saturates the market, although nuclear may do so if it is not followed by something else. The dynamics of the introduction of new sources and the high time constant lead to maximum penetrations of 60 to 70 percent. This is also true for most smaller systems, as will be shown later.

Nuclear achieved only a 1-percent share of primary energy in the zarly 1970s; thus its future penetration rate cannot be distilled from the historical data. In 1977, installed nuclear capacity reached $88 \mathrm{GW}(\mathrm{e})$ (IAEA 1977). Taking an overall utilization factor of 75 percent, the nuclear share in primary energy consumption is about 2 percent.

By 1990, according to the IAEA (1977), power plants currently under construction and planned should be in service; thus, the total installed capacity should be at least $430 \mathrm{GW}(\mathrm{e})$. With a rough utilization factor of 75 percent, this corresponds to a 5- to 10-percent share in 1990, Jepending on whether we use a 2-percent or a 3-percent growth rate of primary energy during the next 12 years. We have chosen a more modest nuclear share to account for possible delays in the construction of the planned power plants: our nuclear scenario prescribes a 6-percent nuclear share in the year 2000. Note that the introduction of SOLFUS in the year 2000 would not influence nuclear until around 2050. 
TORO - PRIMAY ENERTY SUESTITUTION (SHORT DATA)

$F /(1-F)$

FRACTION (F)

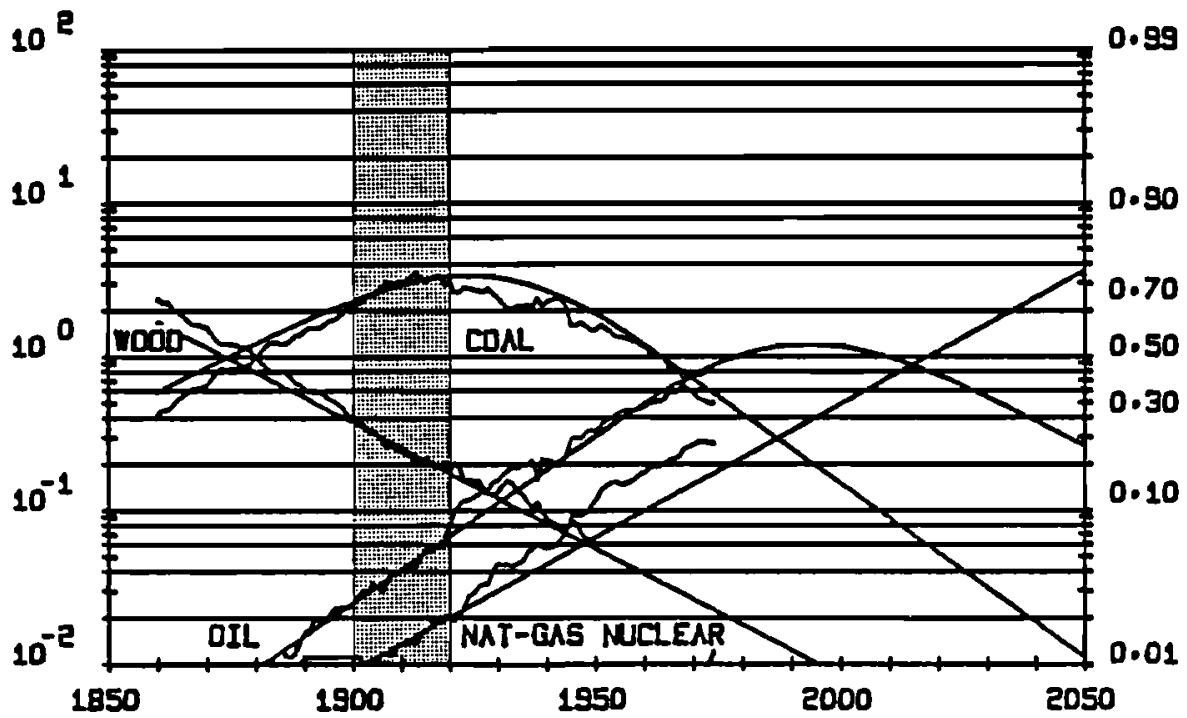

WORLO - PRIMARY ENERTY SUBSTITUTION (SHORT DATA)

$F /(1-F)$

FRACTION (F)

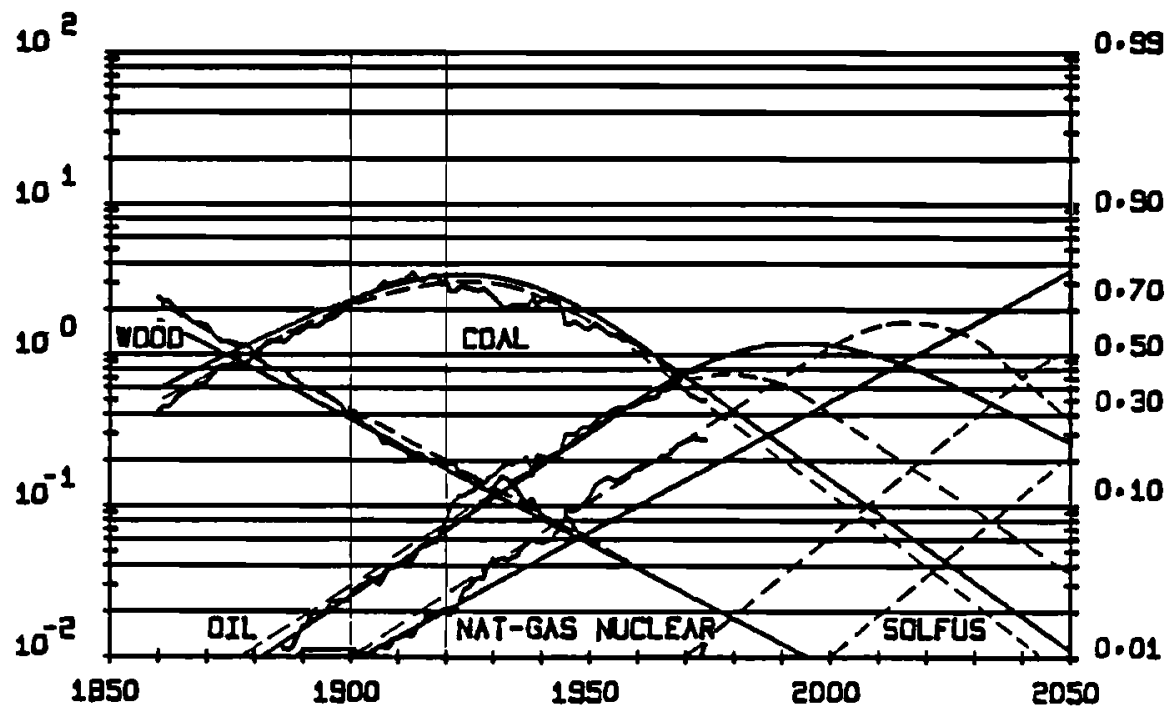


As available statistics are sometimes unreliable, have gaps lasting for long periods of time, or refer to certain energy sources and not to others, we have tried to check the stability of the fitted functions and of the forecasts with respect to restrictions in the information base. The results are very encouraging, showing that the relevant information can be extracted from relatively short data swaths.

Each curve in our system can be fitted with only two points, since only two points are needed to define a straight line. Consequently, the large number of statistical data serve only to reduce noise. However, 20 years of data already constitute an excellent base. We have tried, then, to reconstruct all the periods under examination, using only a time series of 20 years, between 1900 and 1920 . This base has the disadvantage that gas has reached only a 2-percent share and consequently its long-term substitution rate may not yet be established.

The smooth curves fitted to the 1900-1920 data still show an extraordinary agreement with the data outside the historical period. Natural gas deviates somewhat and there is an error in the "prediction" of about 7 percentage points at the end of the period. This may seem relatively large, but it is a prediction made 50 years ahead from a small market share, and with a depression and a war in between!

Because the model does not predict the introduction of new primary energy sources, nuclear does not appear at all in these projections. Yet the absence of nuclear was of no consequence for the 50 years from 1920 to 1970 , and, as shown in the previous figure, nuclear will be of little consequence for the other energy sources until it penetrates 5-10 percent of the market in about 2000 .

These observations are of the greatest importance since they give logical surport to the use of our system of equations for projections into the future. In the lower figure, superposing the curves fitted on a short data base with those fitted on the complete data base shows the relatively small differences. Additionally, whenever the timing and penetration rates of future technologies must be estimated, as for nuclear and SOLFUS, the system of equations serves to establish internal consistency for each scenario.

Superposition of the curves calculated with the short data base (solid lines) and the extended data base (dashed lines) shows the remarkable predictive ability of the short data base over a period of half a century, and illustrates the gradual accumulation of errors. 
VORa - FUE TOCO EXLLUDD

$F /(1-F)$

FRACTION (F)

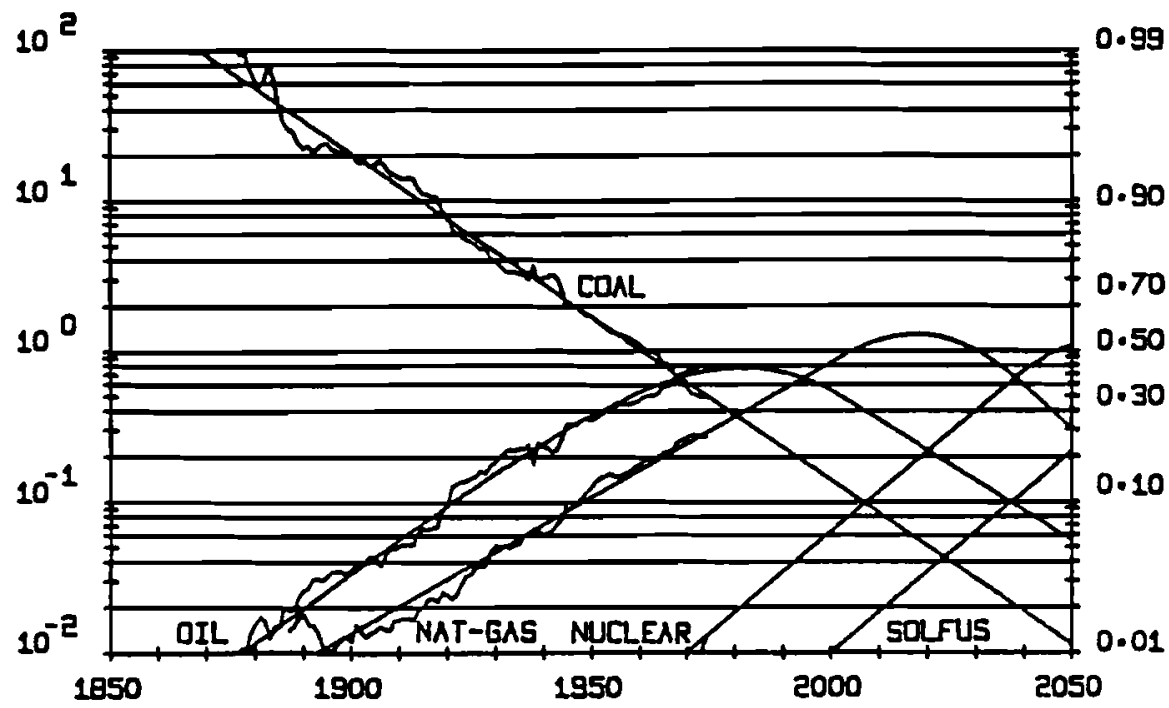

This experiment shows that much information about the total system can be extracted from a structural subset. From the complete data base, we had the impression that wood statistics were too smooth to be accurate, and in a certain measure represent educated guesses of the statistical offices. Consequently, we omitted wood and analyzed the competitive behavior of the other primary sources left in the market. As the figure shows, the logistic description fits the subset perfectly. In the following figure, the curves with and without wood are superposed, to show that little information is lost when wood statistics are eliminated. 


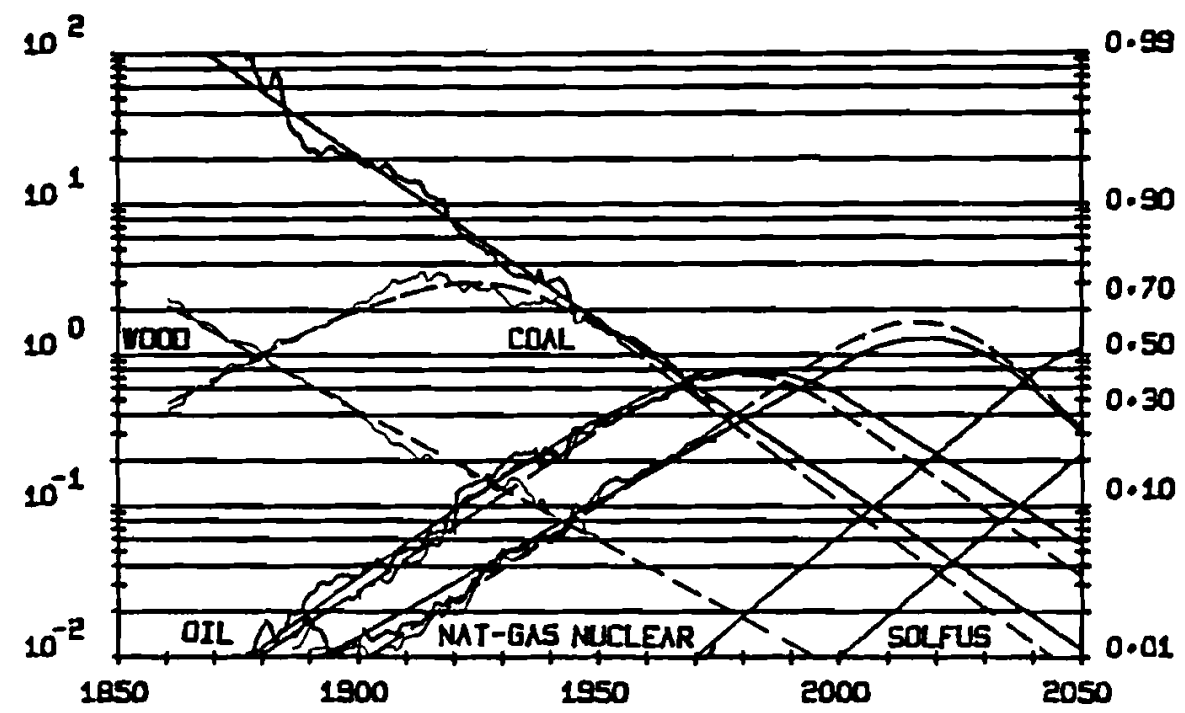

To better appreciate the level of the errors made by eliminating fuel wood data, we superposed the two sets of curves. The differences never went beyond a few percent of the market, showing that key information about the dynamics of the market is contained in and can be extracted from restricted subsets of the original data base. 
VORLO - FAST ANO SLAN MULEAR ENERGY

$F /(1-F)$

FRACTION (F)

$10^{2}$

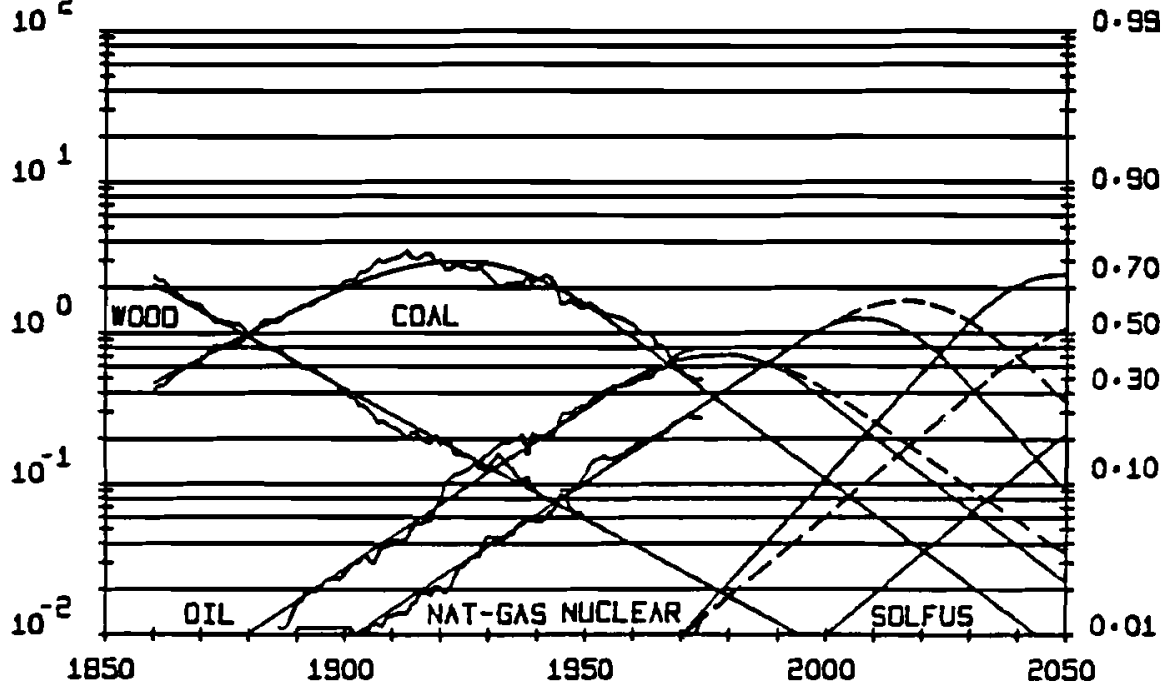


The history of nuclear energy is too short and the market penetration of nuclear energy is too small to provide a reliable indication of the longterm market penetration rate. We made a sensitivity analysis to explore the consequences of this uncertainty. A plot with a nuclear energy share of 6 percent in the year 2000 and one with a 10-percent share in the year 2000 , almost doubling the rate, are superposed.

This figure reveals very interesting properties of the logistic competition. Primary fuels on their way down are insensitive to a change in the rate of newcomers. After the great fuss about nuclear energy tramping into the garden of coal, and coal being reshaped as a tool to stamp out nuclear, this appears very refreshing, if unexpected.

Nuclear appears to interact strongly only with natural gas, presumably preempting the markets into which it could have expanded, and interacts only marginally with oil, which may disappoint those who install nuclear power stations to reduce their need for oil imports. The problem of resource availability that automatically comes to mind is not dealt with here. It appears, however, that the substitution mechanism itself takes care of it. Actually, leftovers seem a stable characteristic of the operation. 
FRG - PRIUARY ENEREY CONSUUPTION

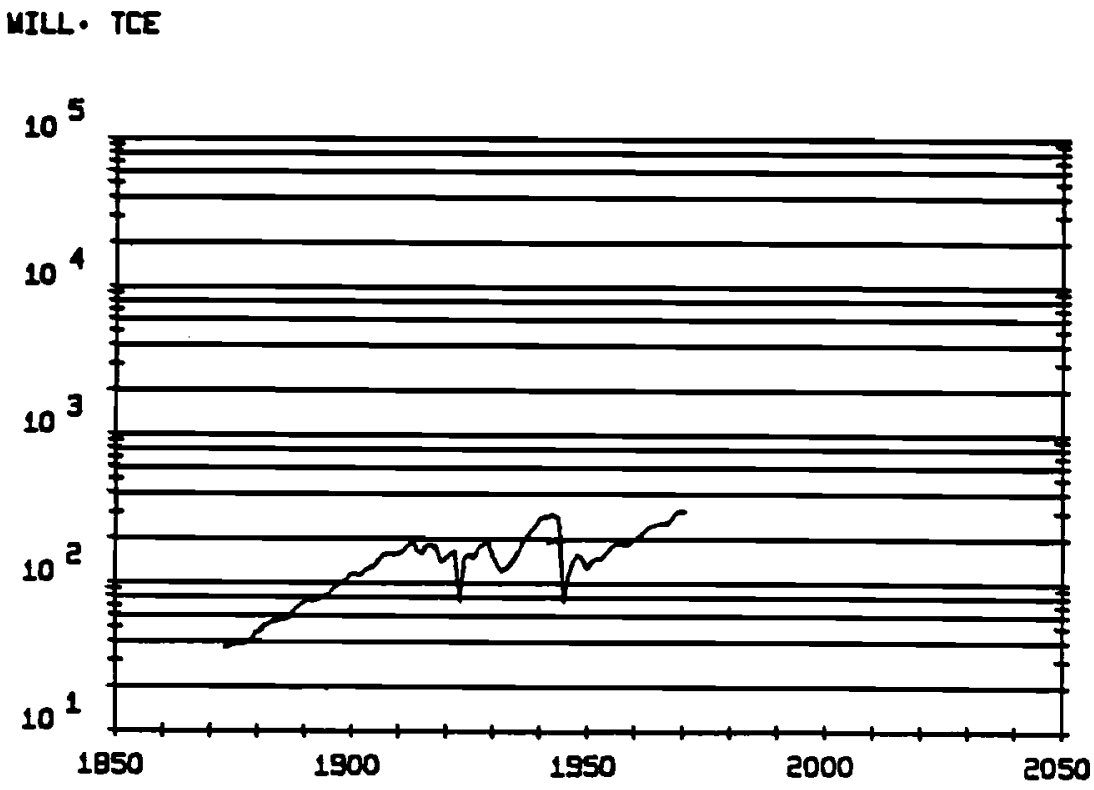

This figure shows the total energy consumption for Germany from 1870 until 1949 and for the FRG from 1950 until 1970. The fluctuations between the two world wars cover a perfect stagnation. It is interesting, if perhaps accidental, that the curve after 1950 matches exactly that before 1910 with the same values and the same growth rate of 4.3 percent. The data after 1950, however, refer to the FRG only.

The original data for the period 1870-1974 are taken from Schilling and Hildebrandt (1977), and the data for 1975 and 1976 were calculated on the basis of energy flow diagrams for the FRG given in Kernforschungsanlage Jülich (1977) for 1975 and by Rheinisch-Westfälisches Elektrizitätswerke (1978).

Data on fuel wood consumption from 1870 to 1950 were taken from Putnam (1953) and were converted from British thermal units (Btu) to tons of coal equivalent (tce). No data on wood were available for the last three decades, but during this time wood has had only a marginal share of the market. Nuclear energy inputs, given in gigawatts of electricity (GW(e)) in IAEA (1977), were converted into tce, with a thermal-to-electric conversion efficiency of 33 percent and a utilization factor of 75 percent. 
unL. Tes

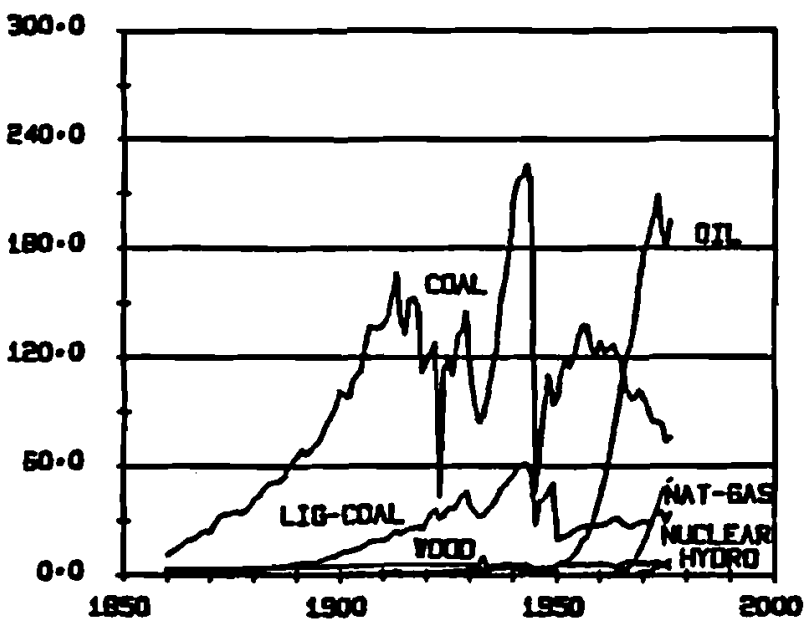

UIIL. Tr.

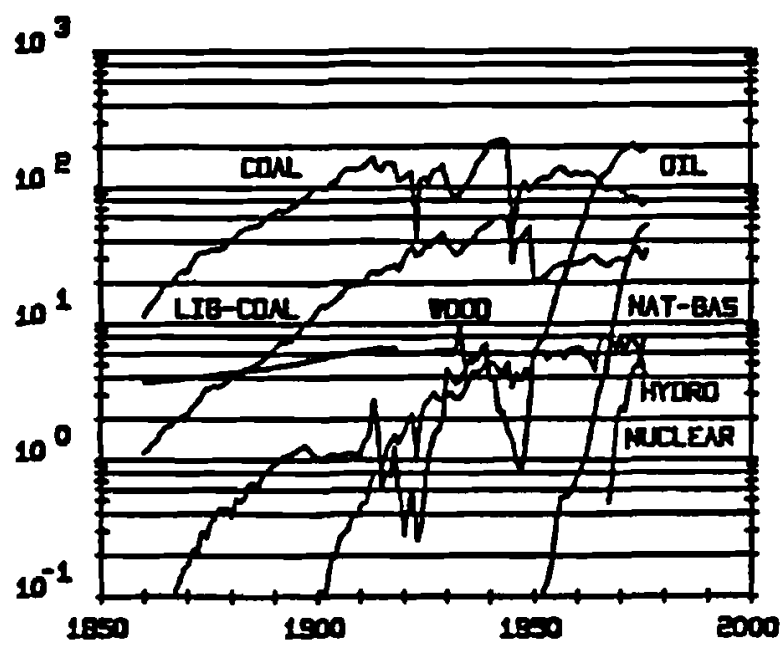

The evolution of energy consumption for Germany and the FRG is shown here for the various primary energy sources, in linear form (top) and in semilogarithmic form (bottom), to emphasize the startup periods. Although a war, a depression, another war, and a partition have had major impacts on total energy consumption, they have had relatively little effect on market shares of the various energy sources, as shown in the following figures. 
$F /(1-F)$

FRACTION (F)

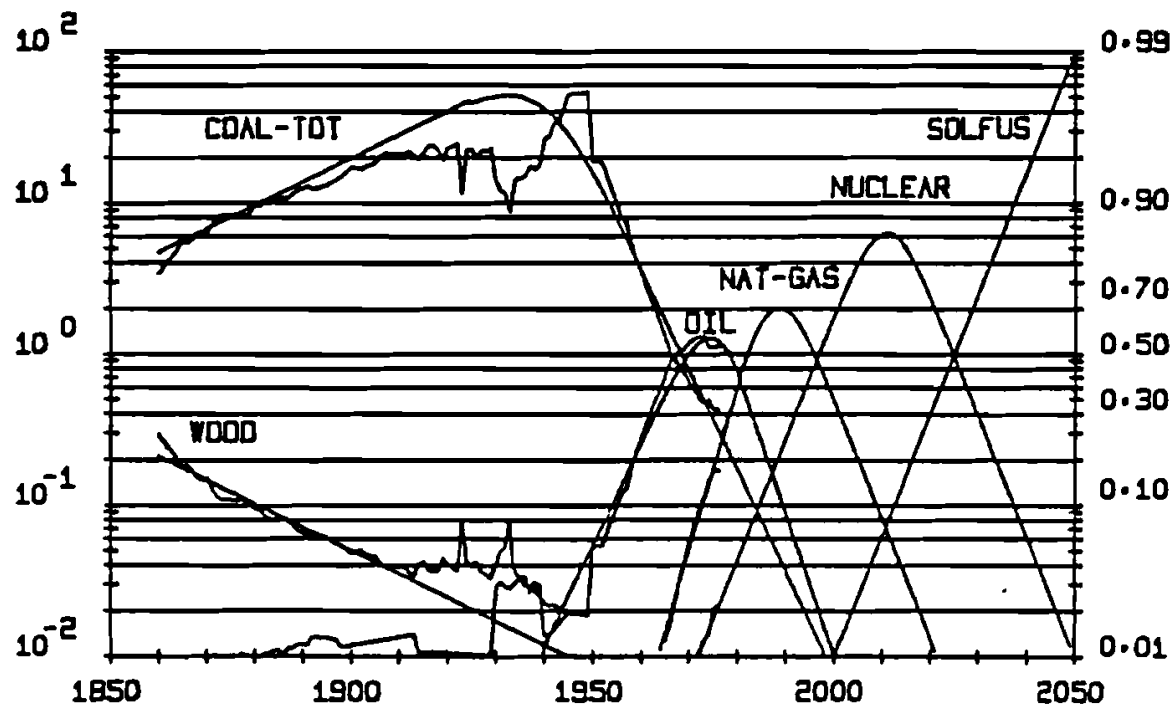


The logistic analysis is reported here first with wood and then without wood. Since wood statistics tend to be unreliable, they are eliminated to avoid a possible source of perturbation. In both cases, the scene appears fully dominated by coal before World War II. The sudden jump of oil to 3 percent in the thirties from a stationary 1 percent is unexplained and could merit further analysis. It may have something to do with preparation for the war. Between 1945 and 1972, substitution proceeded very smoothly and logistically, with oil becoming dominant with a fairly short time constant of about 25 years, and gas promising the same performance in a suspiciously short period of 15 years. The peaking of oil consumption around 1973 in relative and absolute terms could have been precisely predicted with data up to 1965 . Thus, it cannot be attributed to the oil crisis but must result from forces internal to the economy of the FRG. There are, however, two uncertainties hidden in this straightforward projection. First, by analogy with the UK, Belgium, and, up to a point, France, natural gas can continue the fast initial trend beyond the usual 2 or 3 percent before it slows down to its steady penetration rate. No such kink for gas appears in the curve for the FRG. It is possible that the kink may appear later, in which case we will have overestimated its long-term penetration rate.

Second, the nuclear penetration rate was estimated on the basis of historical data. However, due to its relatively low share of primary energy (2.2 percent in 1976) we have checked this penetration rate to see that it corresponds to the number of power plants currently under construction and those planned for the future. The IAEA (1977) gives a total installed capacity of $21 \mathrm{GW}($ th) in 1977 for the FRG; an additional $34.3 \mathrm{GW}$ (th) are now under construction and will be in commercial operation by 1982; and another $65.9 \mathrm{GW}(\mathrm{th})$ are planned by 1985 . Taking a rough utilization factor of 75 percent over this period, these plans would indicate approximately 40 million tce nuclear primary energy equivalent in 1982 and 90 million tce in 1985. Our nuclear penetration rate with a total primary energy consumption growth rate of 4.3 percent per year gives a nuclear primary share of 30 million tce in 1982 and 50 million tce in 1985. Thus, our nuclear penetration rate can be characterized as being somewhat pessimistic on the basis of current plans, and presumably realistic as a lower limit on the future role of nuclear energy in the FRG. The true fate of nuclear should be revealed in the next 10 years.

A SOLar or FUSion (SOLFUS) scenario has been introduced for the year 2000 , with a penetration rate equal to that of nuclear energy. This keeps the system evolutionary and gives an idea about the ultimate effect of the next source on nuclear. Altogether, the FRG appears to behave normally but more dynamically than systems of similar size and structure, such as France or the UK. 


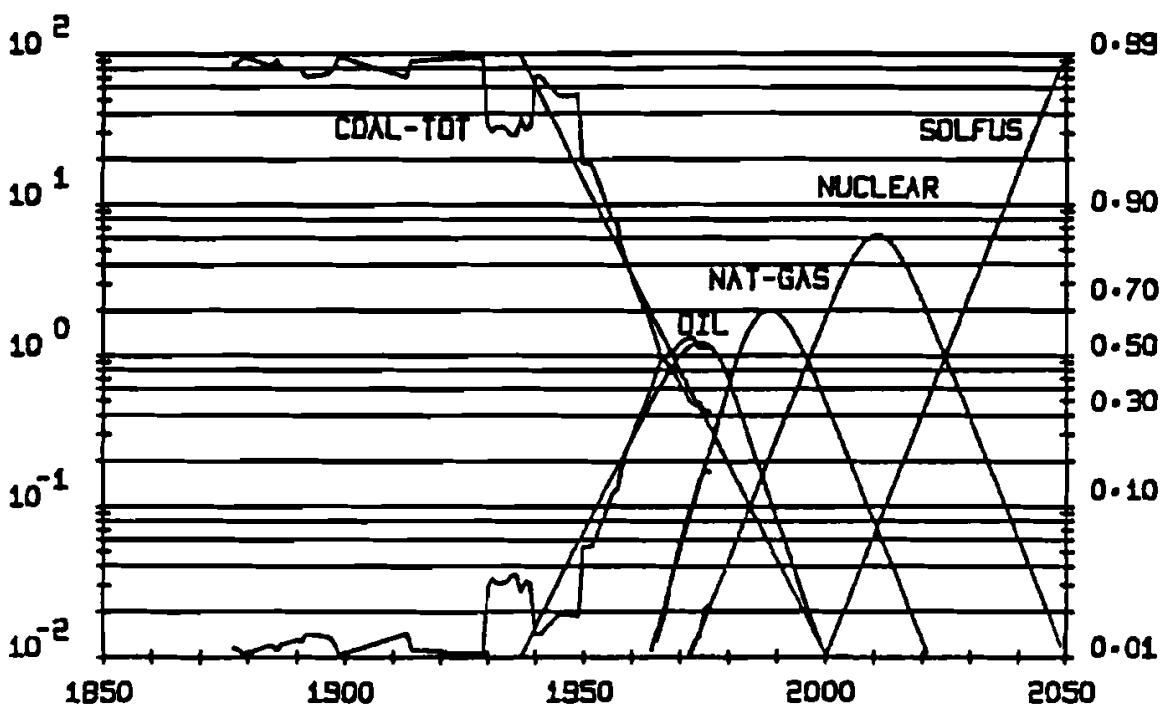

As the statistics on fuel wood are of ten unreliable, we have eliminated wood and analyzed how the other fuels share the market for commercial energy sources. Oil remains at a level of 1 percent for half a century and shows again that actual logistic market penetration does not start until the market has been penetrated by a few percent. An extraordinary feature of the predictive side of the graph is that oil as a primary source of energy will virtually disappear in the year 2000 , a feature common to the UK, the Netherlands, and Belgium. If this happens to be true, what will automobiles run on? Perhaps on LNG, $\mathrm{H}_{2}$, or methanol. 
FRACTION (F)
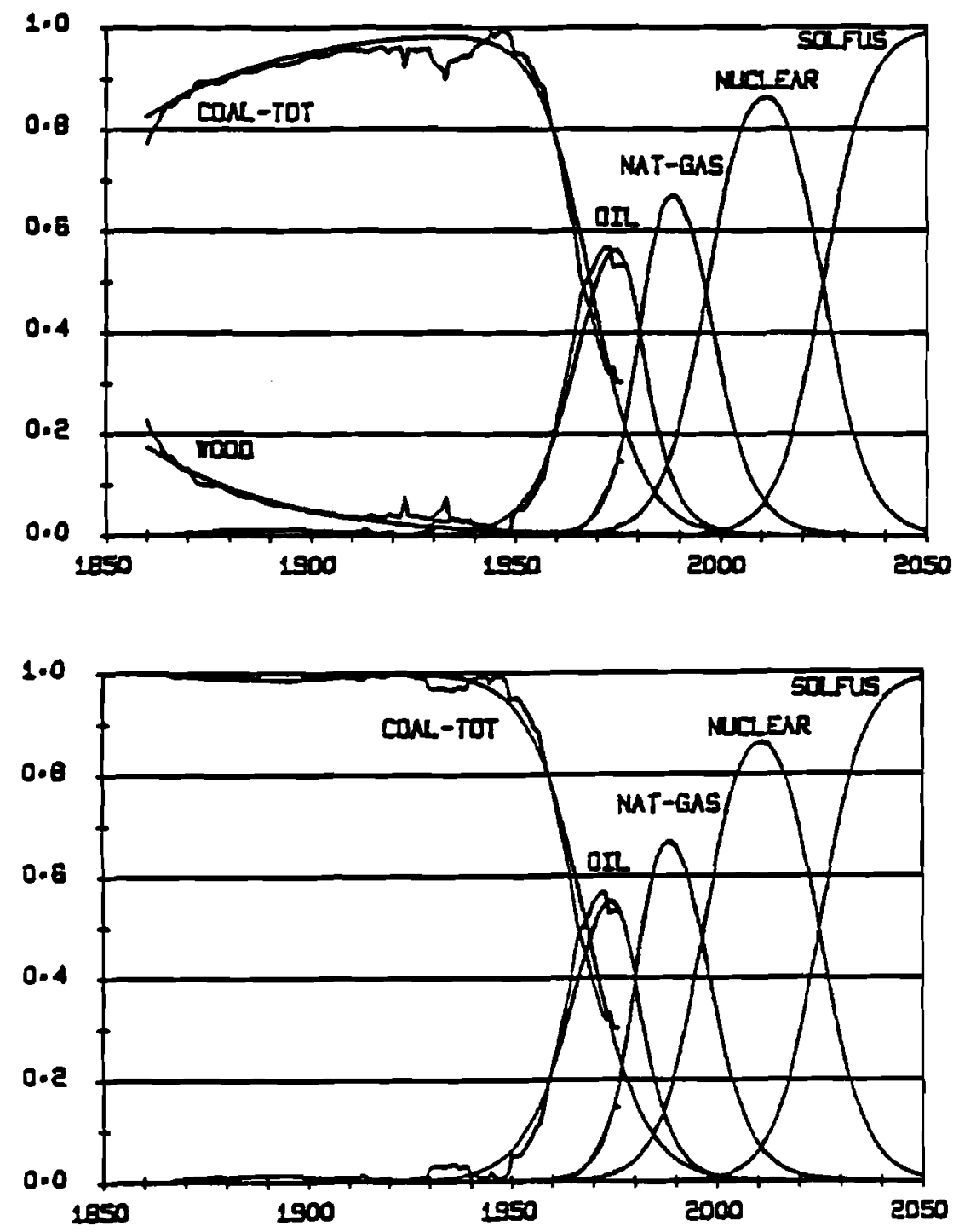

The overwhelming predominance of coal in the German economy prior to 1950 is illustrated again in these linear-logistic plots of the same substitution processes shown in the previous two figures. The upper plot includes wood and the lower plot does not. 
FRS - FRIUARY DMRGY SUBSTITUTION

$F /(1-F)$

FRACTION (F) FRACTION (F)
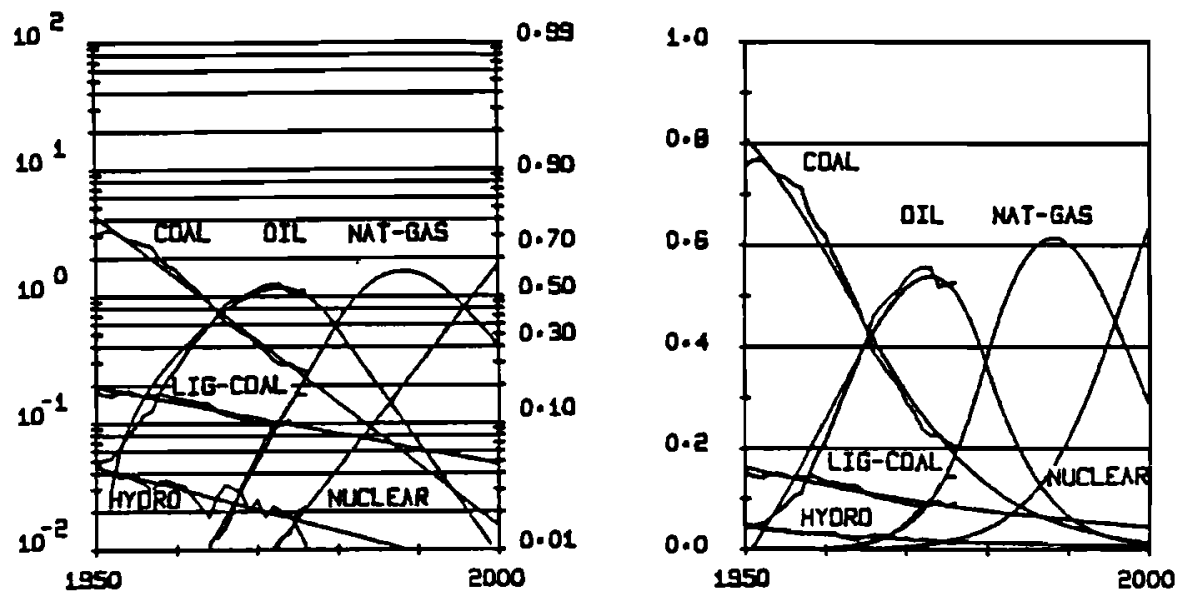

Coal and lignite are usually lumped together in statistics, although, like oil and gas, they are technologically, logistically, and structurally different enough to be considered separately. For the FRG, data are available to treat them independently, which we do in these figures. We also include hydropower, converted to its fuel equivalent by assuming the appropriate thermal power plant efficiency. This separation of the data appears fruitful. Hydropower shrinks in importance, while lignite has its own precise trend and appears to overtake coal in the late eighties. Can it be a source of fuel for cars, perhaps via methanol? 

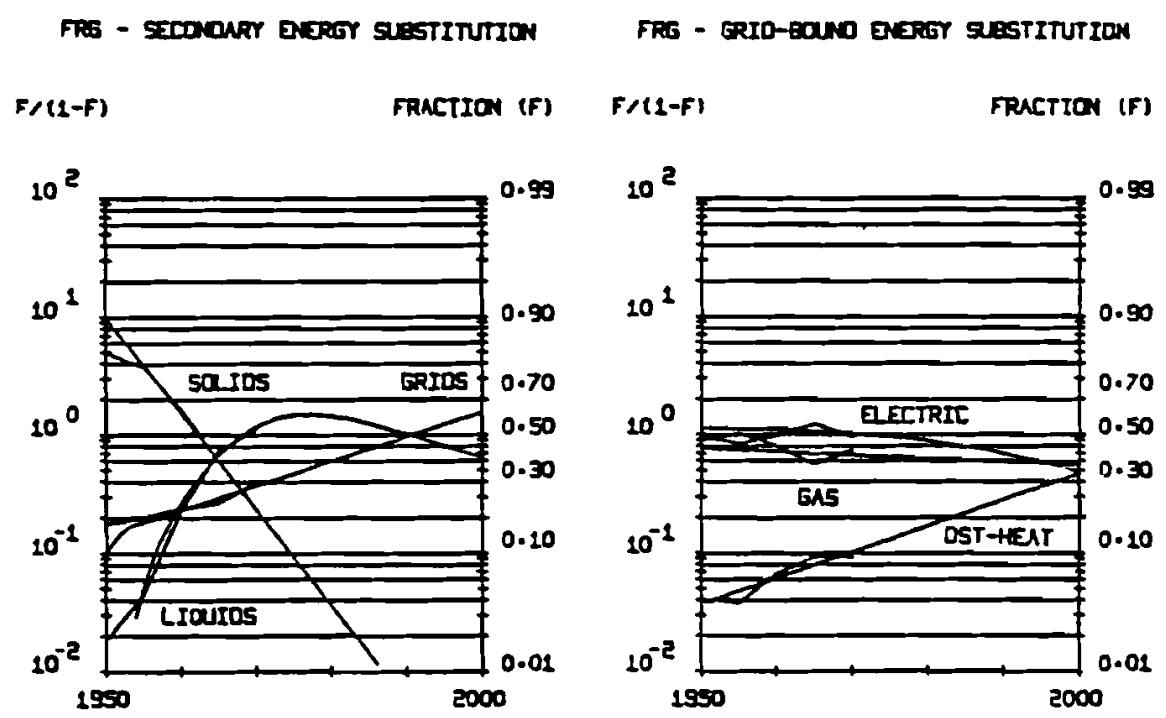

In the same way as we supposed that primary energies are technologies competing for a market, we also assumed that secondary energies behave in the same fashion. The analysis is based on historical data from Sassin (1977).

The left-hand figure shows the market shares of solids (coke, coal, and lignite), liquids (mostly heating oils), and distribution grids (electricity, gas, and hot water) to ultimate consumers in homes, offices, and factories (i.e., excluding the transportation segment of the economy). The right-hand figure shows how the three grid technologies compete among themselves for the overall grid market, revealing a great future for district heating, unless a new system is available in the next 20 years. 
FRG - EECTRICITY GENERUTION GY PRIMURY IMPUTS

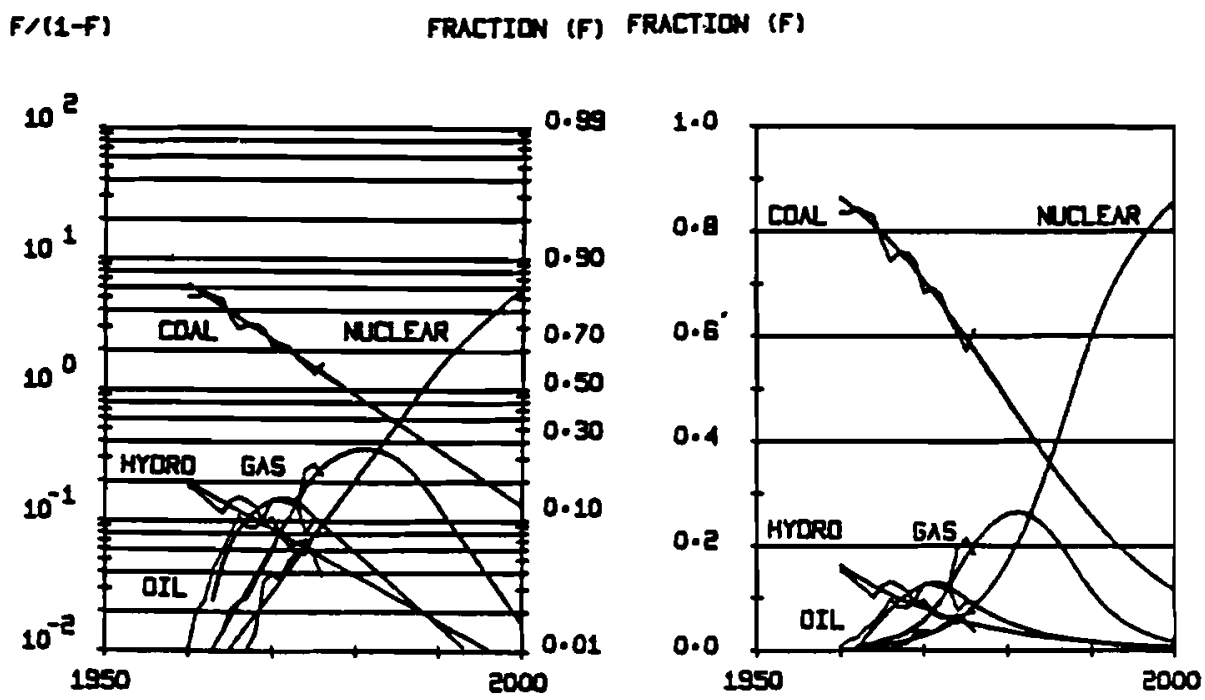


The relatively short data base permits reasonable curves to be fitted. A longer time series would not really help since before 1950 electricity came almost exclusively from coal. The visual impression from the garble of curves is that the FRG electricity industry is undergoing a very fast transformation, with nuclear finally replacing coal in its dominant role with a time constant of about 20 years. If we try to make predictions, oil and gas appear to fill a transitory gap. Hydropower is phased out of the market simply as a result of market expansion.

As nuclear is most suited to baseload generation, having very low marginal costs, a question arises about the utilization of part-time capacity available when this baseload is saturated, which seems to occur in the mideighties. It is not improbable that this may spur the production of synthetic fuels from nuclear energy, and make the disappearance of oil a little more plausible.

In order to cross-check the consistency of the relatively fast phaseout of coal and lignite in the primary inputs, and the relatively more sluggish disappearance in the electricity industry, we made a check with the assumption that the share of primary energy going into electricity production in the year 2000 will be less than 50 percent. This is not illustrated here, but the projections are consistent.

Data for electricity generation by primary energy source from 1950 to 1974 were taken from Atomwirtschaft-Atomtechnik (1976). Data from 1950 to 1958 were only estimates; thus, we did not use them. The original data are given in gigawatt hours of electricity output. For the purpose of comparison with primary energy consumption, we have converted the data into millions of tons of coal equivalent. However, this conversion is not very exact since we did not account for the different efficiencies of various fuels. Instead, we have taken an overall average efficiency for all inputs. The errors resulting from the approximate conversion to million tce are small. Data for 1975 and 1976 were taken directly from RheinischWestfälisches Elektrizitätswerke (1978) and Kernforschungsanlage Jülich (1977) in millions of tons of coal equivalent. 


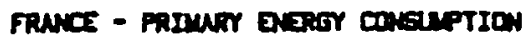

MIL. TEE

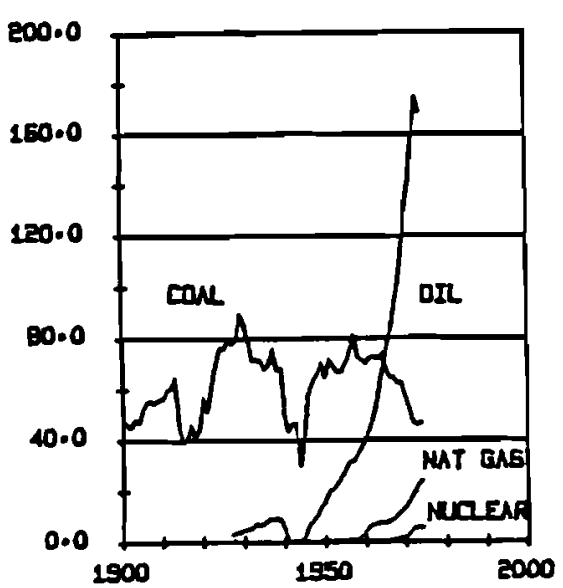

UII. TLE

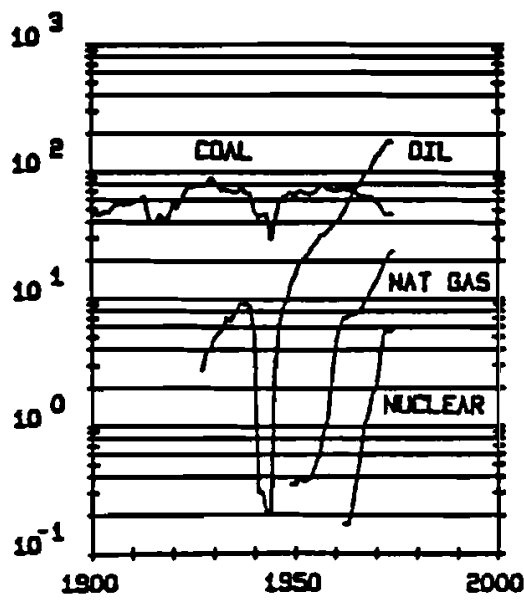

Two sets of data were used for analysis of the substitution dynamics of primary energy for France. The first set is from Weitsch (1976) and was available for the period 1900 to 1974 . The second set comes from the OECD (1976). Time series for coal, oil, natural gas, and nuclear are reported in millions of tons of coal equivalent for the period of 1960 to 1974. Oil data contain crude oil and petrochemical products. The agreement of the data sets for the overlapping period of 1960 to 1974 is very good. The first data set is illustrated here in linear and semilog form to amplify the starting period. The second data set is considered later in the report. 
FRANCE - PRIMARY EIJRGY SUESTITUTION

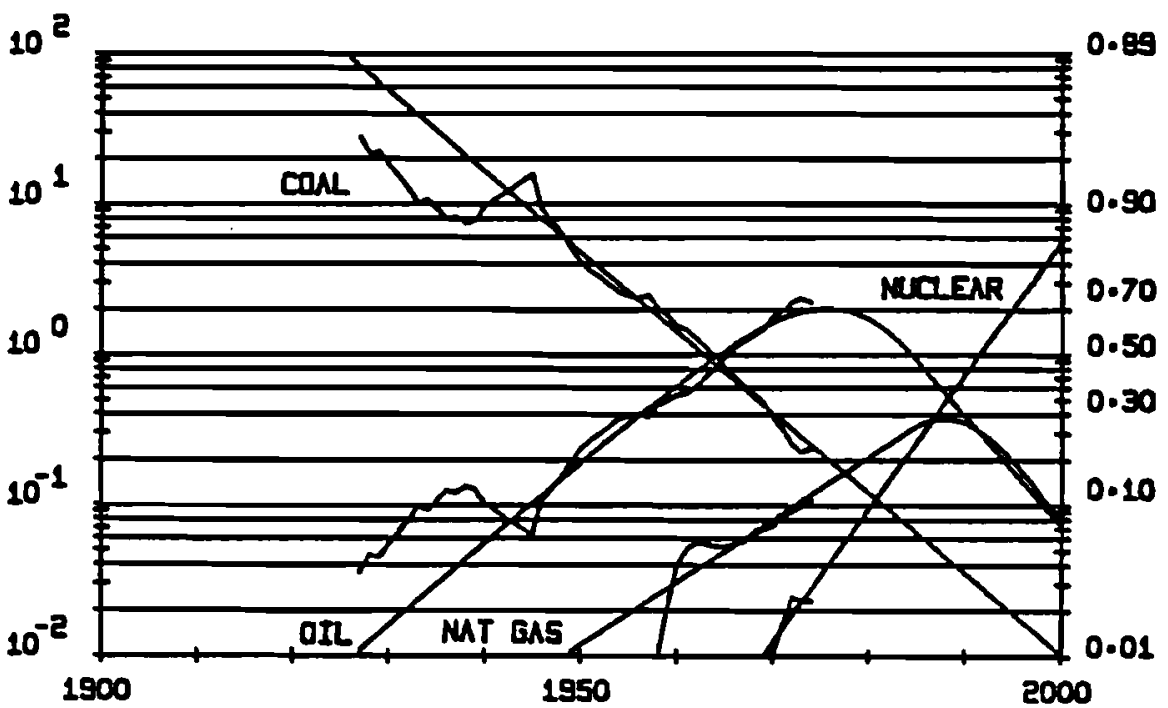

This example of primary energy substitution indicates that France will manage a relatively smooth transition without the very problematic issues seen in the examples for the FRG. Oil was introduced much earlier and will be phased out later, leaving more breathing space for a decision on automobile fuels. The dependence on oil has reached a maximum level of about two-thirds of the total energy consumption. This presumably has greatly stimulated the decisions in favor of the nuclear option; nuclear penetration, however, seems to be slightly slower than in the FRG. Natural gas, which started its career at approximately the same time as in the FRG, may then last a little longer and play the same important role around the year 1990. The very fast growth of natural gas up to about 7 percent of the market might be interpreted as the manifestation of an intensive external support (by the state?), a hypothesis that is yet to be verified.

A peculiarity of the curves is the twist corresponding to World War II. Everything would fit again if we assume that the French system hibernated during the military occupation, and if we "cancel" the 5 years that it lasted. From the linear-logistic plot, France seems to be a much less dynamic system than the FRG. Time constants are in fact about 50 years. 
FRANCE - PRIUARY EMERY SUPSTITUTION

FRACTION (F)

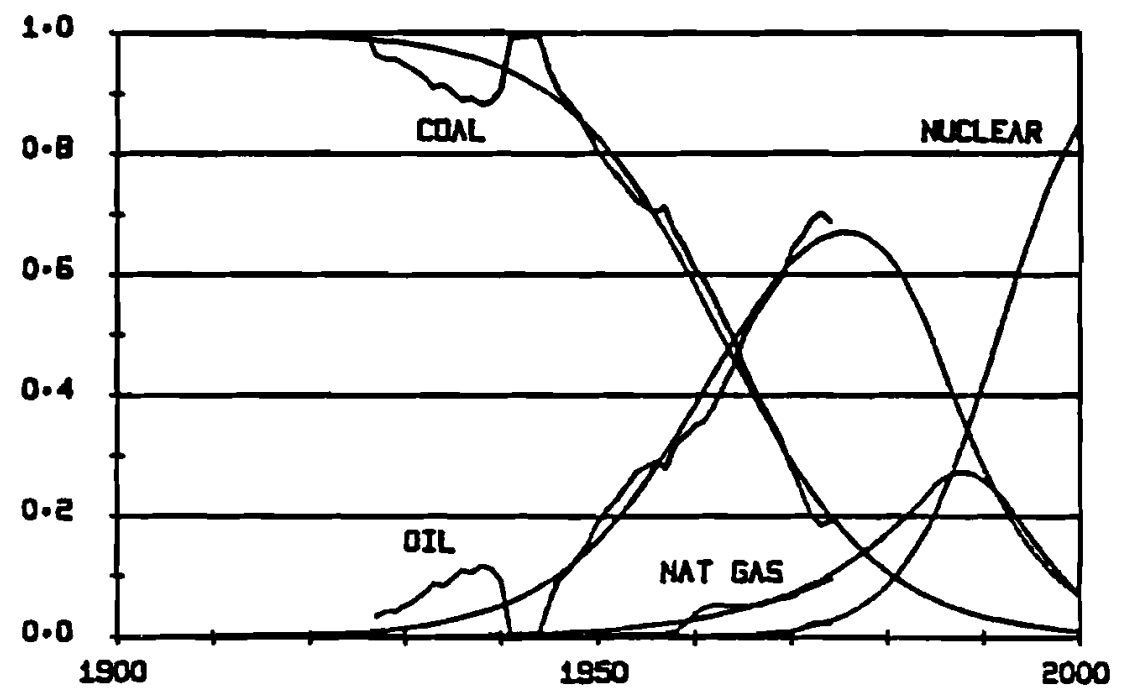


As there are so many uncertainties facing the deployment of nuclear energy in the next decade, which is so critical for defining the pace for the rest of its penetration, we made a sensitivity study adopting two other plausible hypotheses. As expected, the penetration of gas is strongly related to that of nuclear, but even oil is strongly influenced. It can be deduced that nuclear is really a hot point in the energy policies of France.

Nuclear energy controlled more than a 2-percent share of primary energy in 1972 after 2 years of very steep growth from a 1-percent share in 1970. This corresponded to $9.7 \mathrm{GW}(\mathrm{th})$ installed capacity reported by the IAEA (1977) for 1972. According to the same source, additional plants with a total of $58.2 \mathrm{GW}(\mathrm{th})$ installed capacity are under construction, with commercial operation expected by 1981 . Together, this makes a total of $68 \mathrm{GW}($ th) installed capacity by 1981 . Assuming a very high historical growth rate of energy consumption of 5.6 percent per year (1960 to 1974) and a power plant utilization factor of 75 percent, the nuclear share will be about 14 percent of primary energy in 1981. This calculation shows extremely rapid nuclear construction rates, and if we assume a lower energy demand during the next decade, the nuclear share would be even higher. If historical rates for other substitutions also apply for nuclear, its penetration would be much slower: 8 percent in 1980. We used that rate in our scenario, which therefore should be considered a very prudent one. 
UK - PRIMARY ENERGY SESTITUTION

$F /(1-F)$

FRACTION (F)

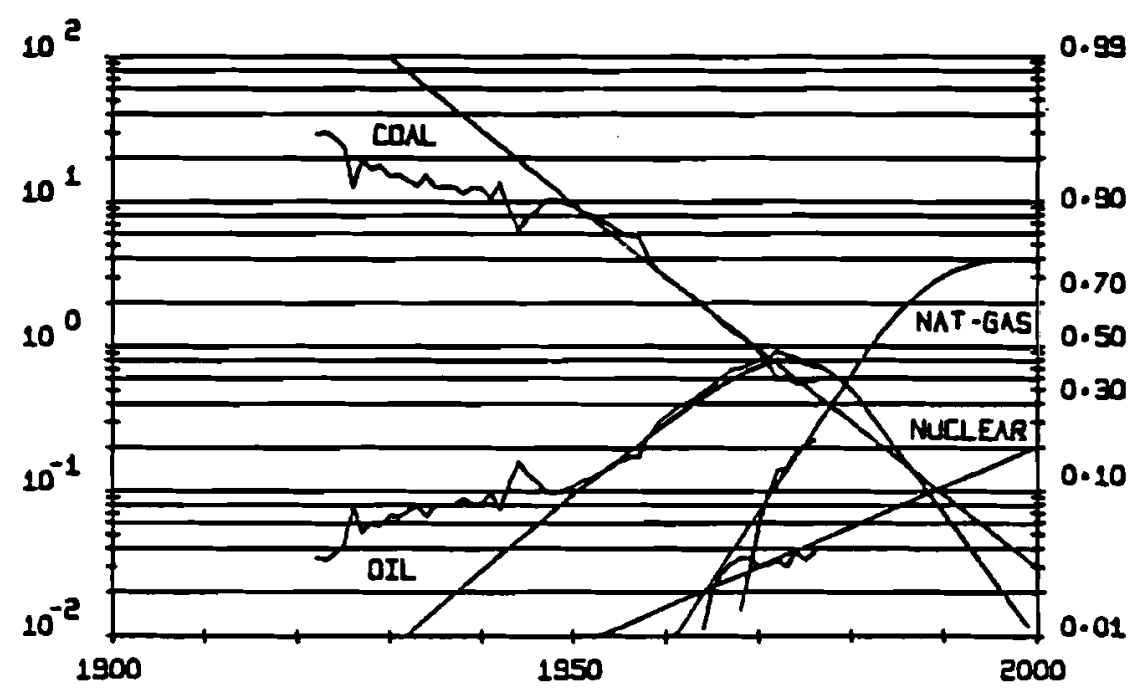

Historical data on consumption levels of coal, oil, natural gas, and nuclear energy for the United Kingdom come from three sources. The period of 1860 to 1950 has been taken from Putnam (1953), from 1950 to 1974 from Ormerod (1976), and 1975 and 1976 from the UK Department of Energy (1976, 1977). Data from Ormerod, however, are reported as fractional shares and therefore absolute levels are not plotted here. According to Putnam, fuel wood has never been an important energy source in the UK except for some use of charcoal. It is not considered in our analysis.

The primary energy substitution is marked by the dominance of coal in the energy market during the last century. Even in 1950, it still contributed 90 percent of primary energy consumption. From 1950 on, the substitution proceeded at high rates. By 1970 , oil already controlled a 50-percent share, and natural gas had 10 percent, starting at 1 percent in 1968. However, the natural gas penetration curve has a kink in 1970, which we assume to be indicative of smaller substitution rates to be observed in the future. The very high pre-1970 trend could be explained by the already-existing gas distribution network being fed by city gas, i.e., mainly from coal, which natural gas simply took over and saturated by 1970, so it did not face the usual growth limitations of a new technology. Therefore, we use only points after 1969 to estimate the natural gas penetration trend. 


\section{UK - PRIMURY ENRRG SUESTITUTION}

\section{FRACTIDN (F)}

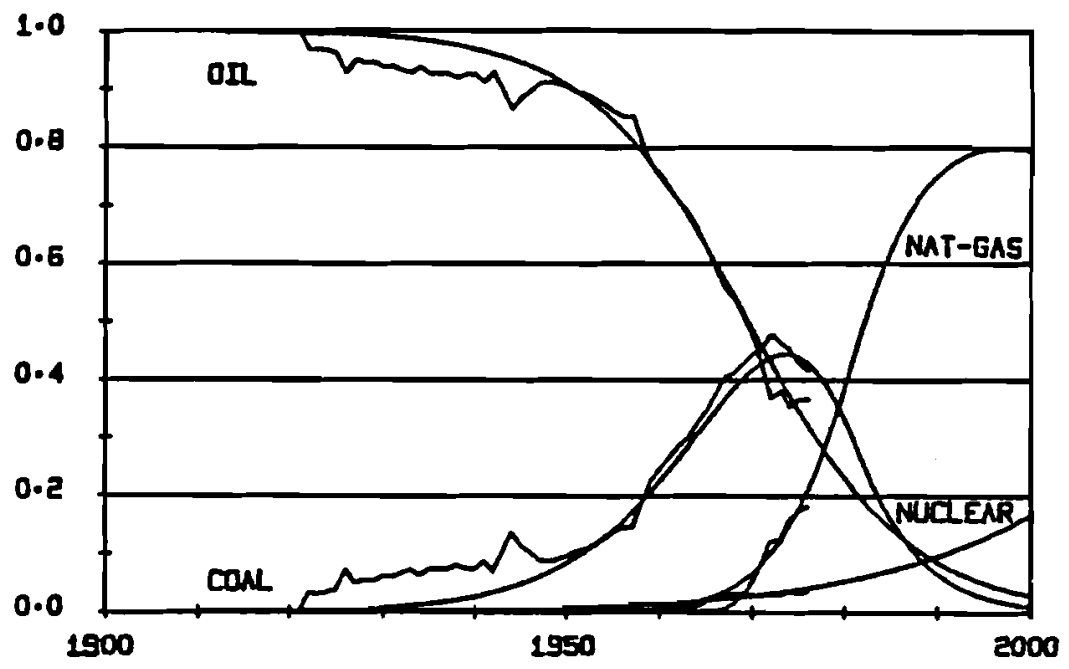

This plot shows that although nuclear energy in the UK had a very fast start in 1964, later it slowed down considerably. Today there are $24 \mathrm{GW}(\mathrm{th})$ of installed nuclear capacity, which at the current utilization rate is about 4 percent of primary energy consumption. Additional plants with a combined capacity of $9 \mathrm{GW}(\mathrm{th})$ are under construction and expected to be in commercial operation by 1979 . Another $3.23 \mathrm{GW}($ th) from nuclear plants are planned by 1986 . This makes a total of $36.3 \mathrm{GW}($ th) installed capacity to be available by 1986 . With a utilization factor of 75 percent and the current growth rate in energy consumption of 3 percent per year, this would give a 7-percent market share by 1986; we assumed 6 percent. 
LSA - PRTum gerer conguption

MIU. TEE

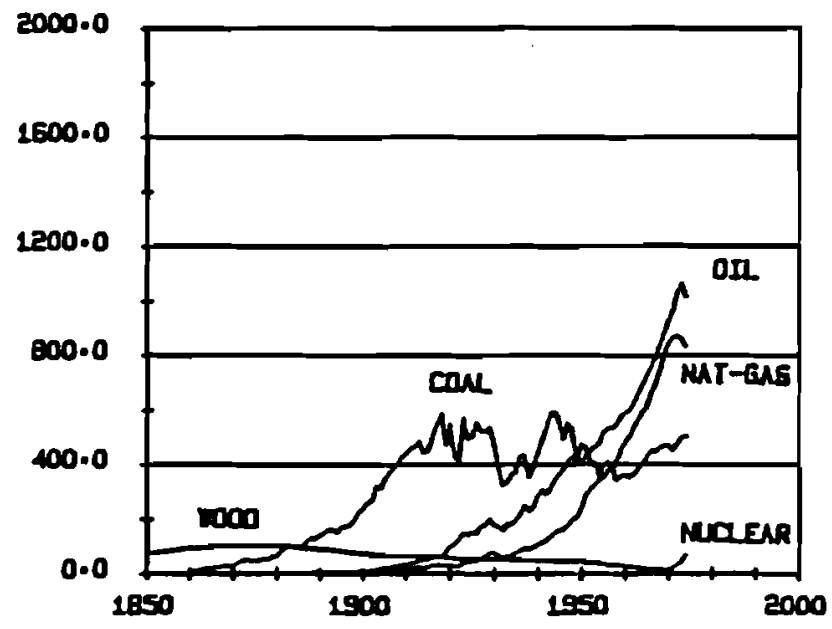

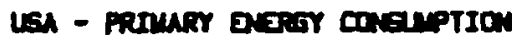

unL. Tres

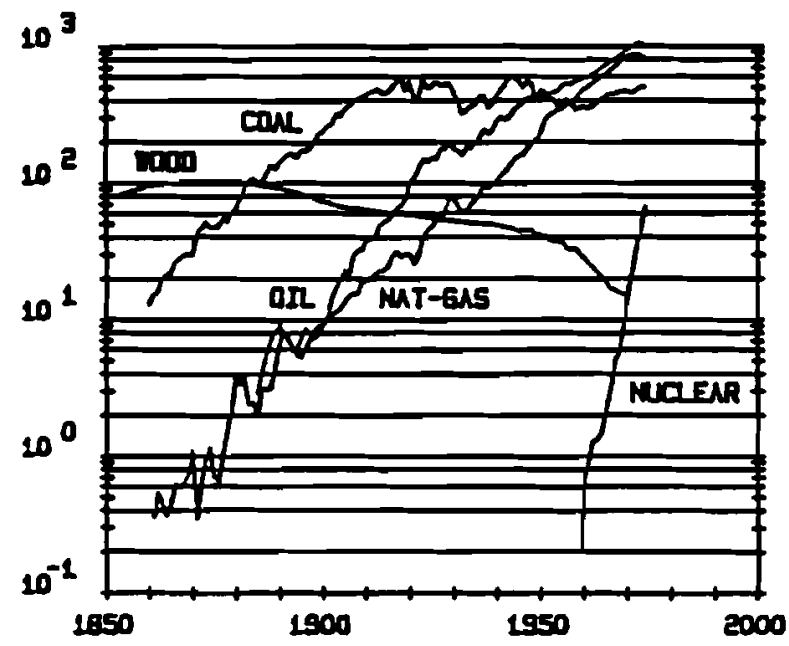


The historical data on primary energy consumption in the United States since 1860 were taken from Schilling and Hildebrandt (1977) for coal, oil, natural gas, and nuclear energy. All data were reported in millions of tons of coal equivalent except nuclear energy. Nuclear consumption rates were reported in millions of kilowatt hours, and we converted them to million tce.

The fuel wood time series come from the U.S. Bureau of the Census (1975a) for the period from 1860 to 1970 . The wood consumption after 1970 was neglibible; thus, it was not necessary to add the last few years. The source we used for the data on wood from 1860 to 1945 was Schurr et al. (1960), who in turn used two different sources: from 1850 to 1930 , Reynolds and Pierson (1942), and from 1935 to 1955, the U.S. Department of Agriculture (1958). Thus, the discontinuity in the penetration rate of fuel wood in the 1930s could be attributed to discrepancies between the two sources. 
FRACTION (F)

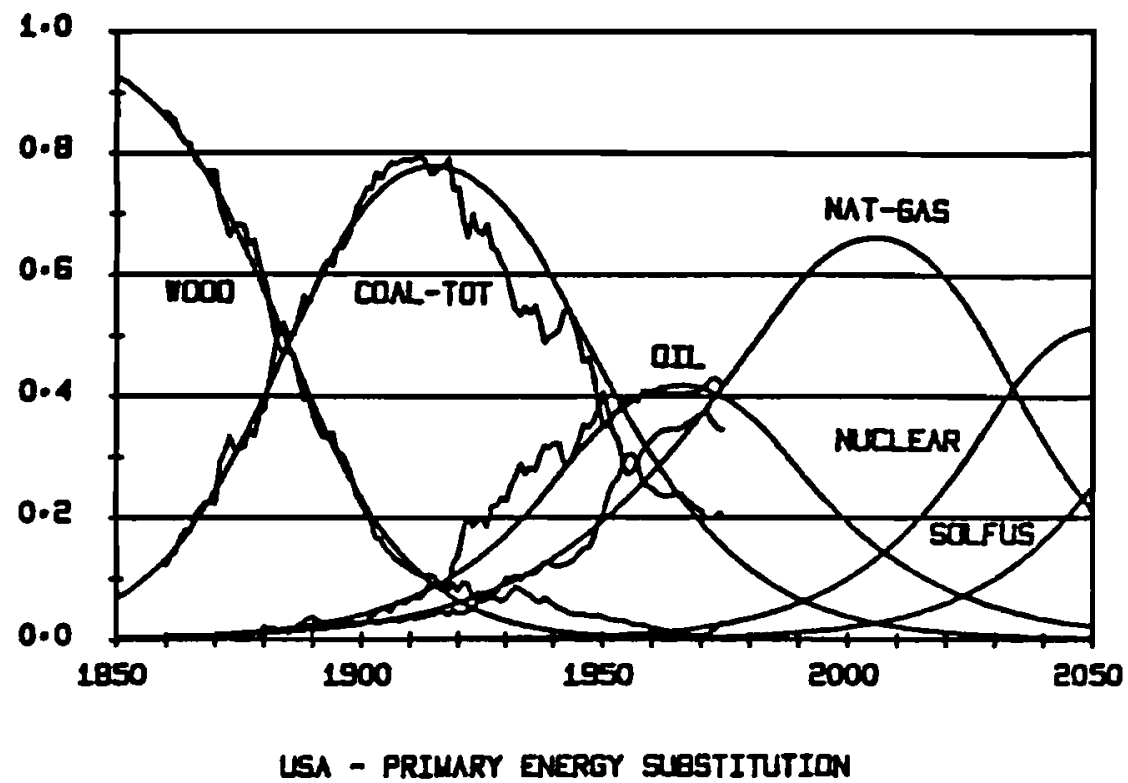

$F /(1-F)$

FRACTION (F)

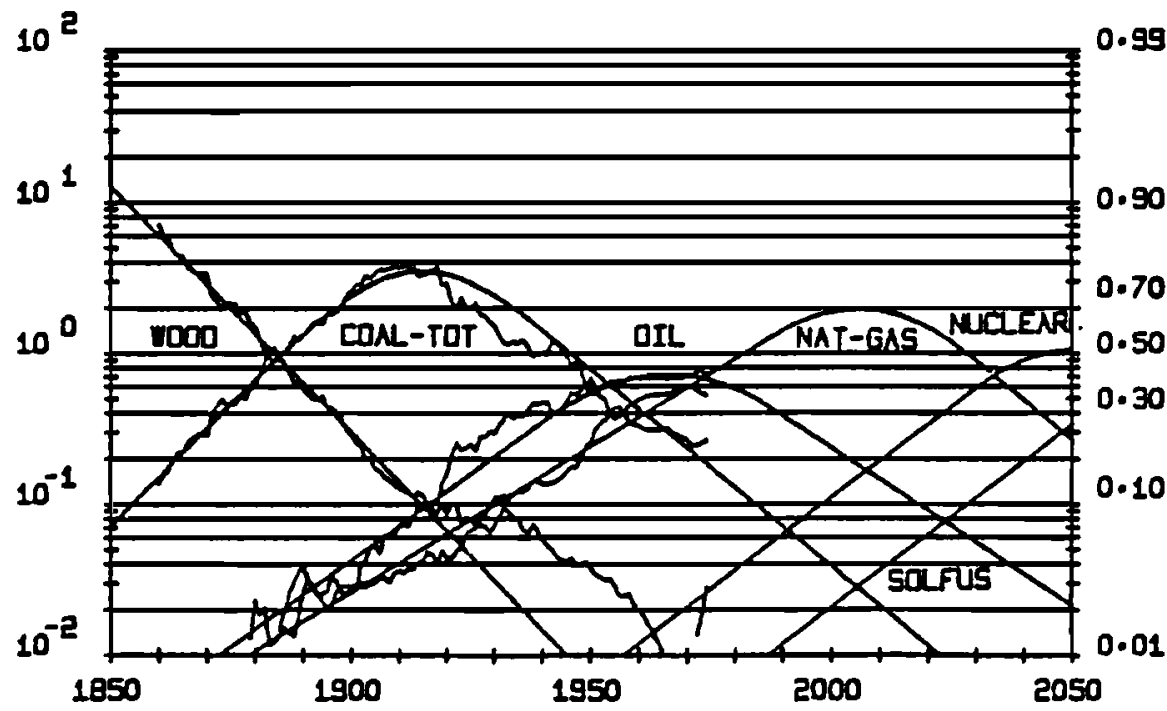


The logistic analysis again makes order out of the mess of statistical data. Substitution appears to move extremely smoothly until 1920 (facing page, top), in agreement with other economic indicators. Coal peaks around that date and oil at the beginning of the 1960s, 40 years later. As early as 1900 , both peaks could have been predicted with good precision; consequently, they are not linked to forthcoming events like wars or embargos. Here, as in all the other cases examined, embargos and large price increases actually produced disproportionately small dents in the curves. The deviation in the lowest part of the wood curve is connected to a change in the statistical source, and most probably due to a change in the accounting and estimating method.

At the bottom of the facing page is a log-logistic plot of primary energy substitution in the United States. One thing left to be explained is the sudden rise in oil production, much above the trend line, essentially during the depression years. This rise induced a corresponding low share of coal, but it did not affect gas. The analysis should perhaps look deeper into the possibility that rapid introduction of automobiles may have caused the perturbation. The striking fact in the process, however, is that after a while, the perturbation was reabsorbed and the secular trend resumed in 1940, 20 years later! This again points to a system memory and clocks!

Contrary to all other predictions, natural gas appears to be the dominating energy source for the next 50 years, which leads to the question whether the United States will import more natural gas in the form of LNG, increase imports from Canada and Mexico, or whether the numerous less accessible sources, like geopressurized zones, will be exploited.

The nuclear market share in the United States was about 3 percent of the primary energy in 1974 and about 5 percent in 1977. This, however, may still not be enough to determine the long-term trend of nuclear penetration rates. By 1990 , there should be about $610 \mathrm{GW}(\mathrm{th})$ installed capacity. This estimate is based on the power plants currently under construction and those planned to be in service by 1990 (IAEA 1977). With the longterm energy consumption growth of 3 percent per year, this would imply a 15-percent share in 1990, assuming an overall utilization factor of 75 percent. To account for all possible delays, we assumed a 10-percent share by the year 2000 in our nuclear scenario.

We have also included an alternative future energy source (SOLarFUSion) that enters the market in 1990 with the same penetration rate as nuclear. There is no basis whatsoever for this assumption, except that a new source could not reach a 1-percent market share before then. As in the world case, a change in the rate of penetration of nuclear will not change the situation of oil, and only after the year 2000 will it change that of natural gas. 
une. Net TONS
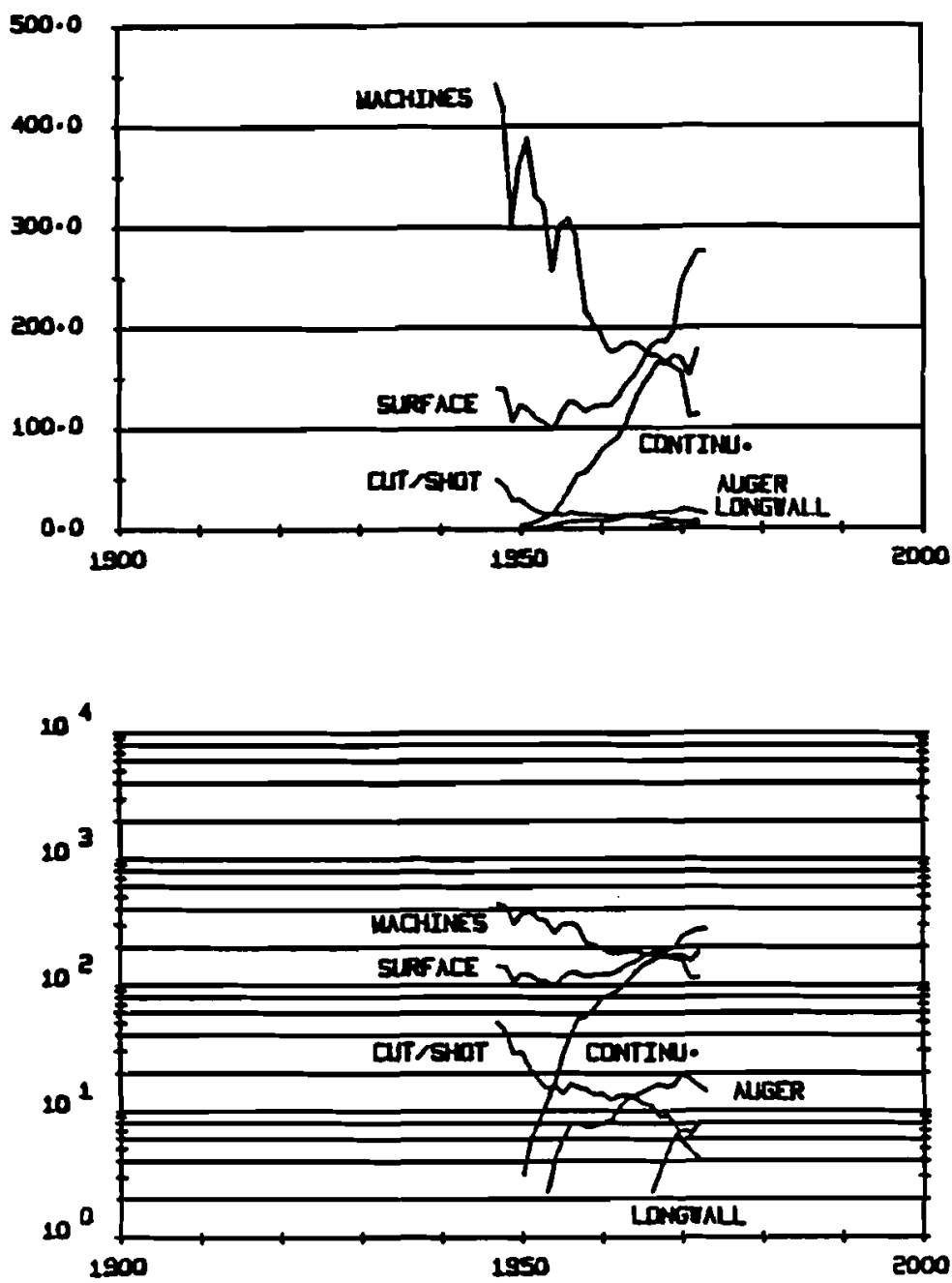

Key:

CUT/SHOT - cut by hand and shot from solid CONTINU. - mined by continuous mining machines LONGWALL - mined by longwall machines MACHINES - cut by machines AUGER - mined at Auger mines

SURFACE - from surface mines 
The evolution of mining techniques in the United States is examined here. It is a very appropriate field for logistic substitution analysis. In these two figures, the amount of coal extracted according to the various techniques is reported on linear and semilog coordinates. As usual, no simple patterns appear. 


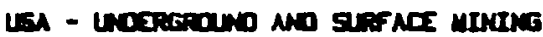

$$
F /(1-F)
$$

FRACTION (F)

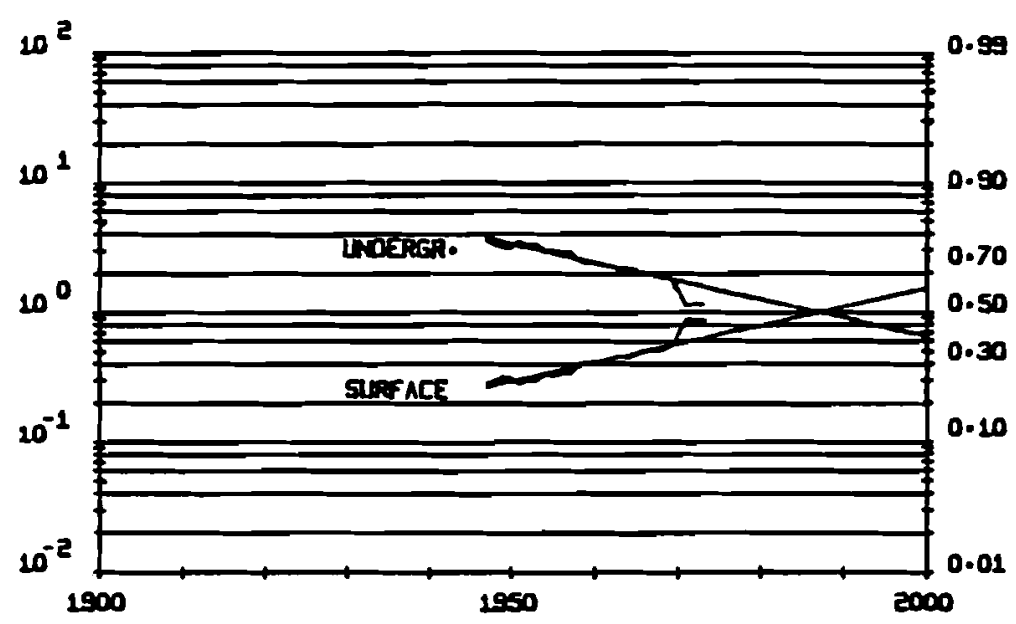

FRACTIOS (F)

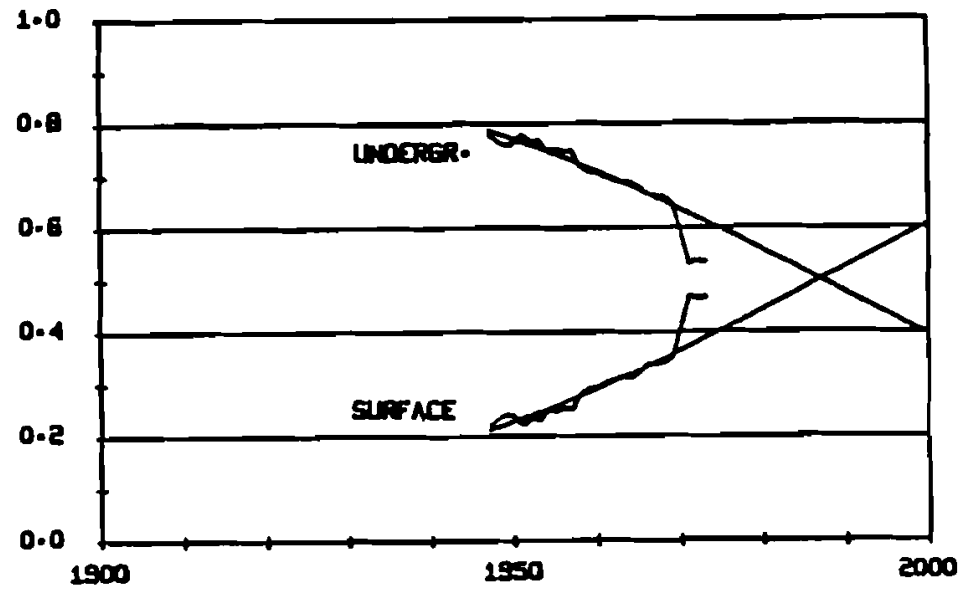


LSA - COAL PROOUCTION GY MININE METHOO

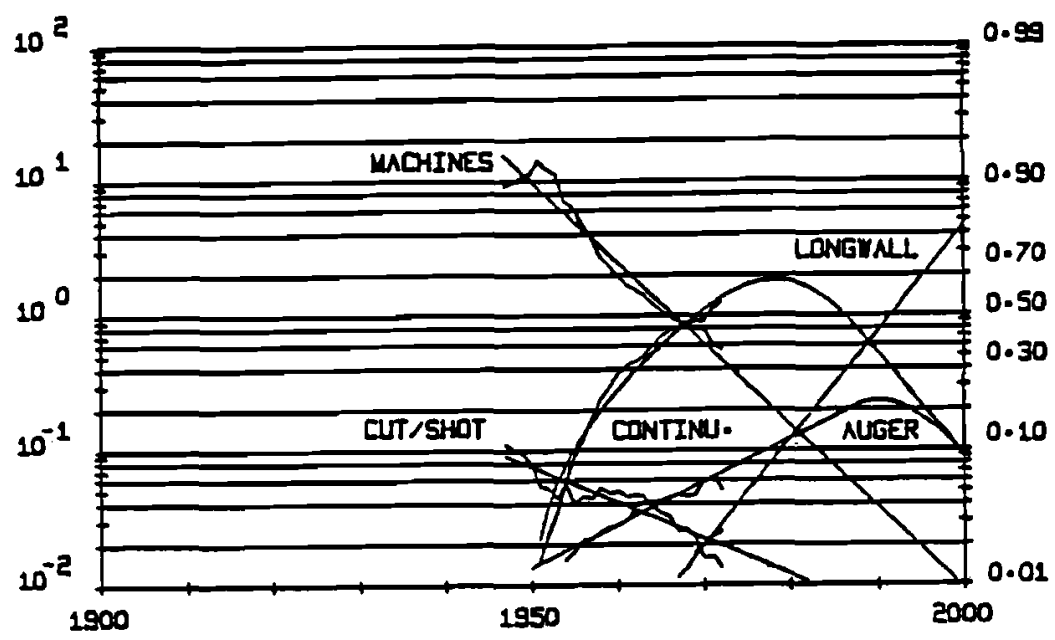

Due to the increasing dominance of strip mining, the competition between strip mining and underground mining is dealt with explicitly (see facing page). A check of the total amount extracted shows that the sharp kink in the logistic plot is due to a sudden drop in deep mining production. These sudden drops are not new in a socially turbulent structure like the U.S. mining industry, but this time it may be due to the introduction of stringent safety rules in the mines. Most probably, the perturbation will be reabsorbed in a few years. If not, deep mining would disappear in the United States in 1980, a very unlikely if not impossible occurrence. Strip mining legislation seems to bring in the corrective reaction.

As deep mining presents such an array of competing technologies, it is interesting to analyze their struggle, leaving out all surface mining techniques except Auger, which could be considered as both underground and surface technology. The longwall technology becomes dominant in the next 20 years, winning the last battle of a lost war, as underground mining seems bound to disappear in about 50 years.

With ups and downs, coal production in the United States stayed constant over the last 50 years at a level of about $0.5 \cdot 10^{9}$ tons/year. Since the phaseout of coal in the United States is a slow process, during the next 20 years, the U.S. mining industry should equip longwall mines for production that is slightly larger than the total production of FRG coal mines now. The abbreviations are defined on page 42 . 
LSA - MATLRL BAS CONGUPTION BY SETLRS

F/(1-F) Fruction (F)

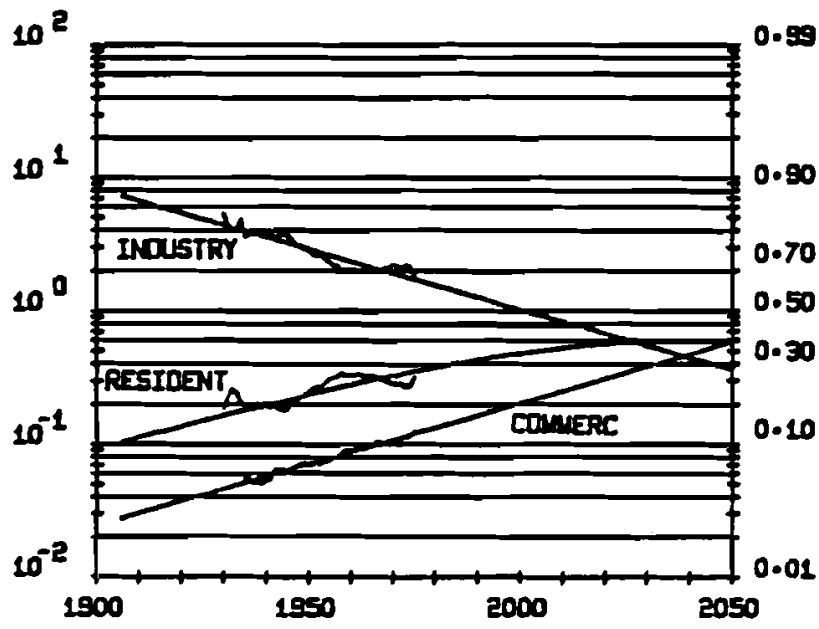

When we view the system through dynamically competing subsystems, we may think that different branches of the economy compete for the same resource, a statement much in line with the Weltanschauung of economists and laymen. In this spirit, we made a logistic analysis of the shares of natural gas consumption of three large parts of the U.S. economy: the industrial, the residential, and the commercial.

It appears that the small consumers are gradually winning a larger share of natural gas, which is quite reasonable in view of how simple it is to use and how little it pollutes. The process of competition, however, appears to have long time constants, and only in the year 2050 will the natural gas input be equally distributed among the three competitors. 


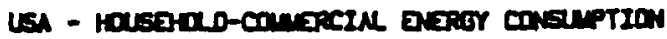

TEA BN

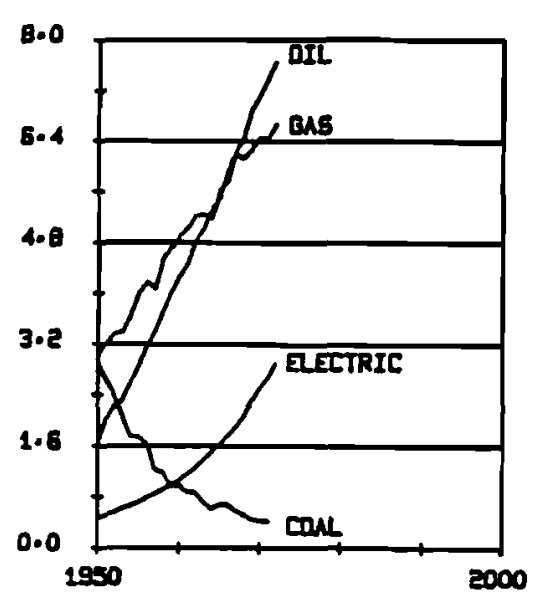

E/(1-F)

FRACTION (F)

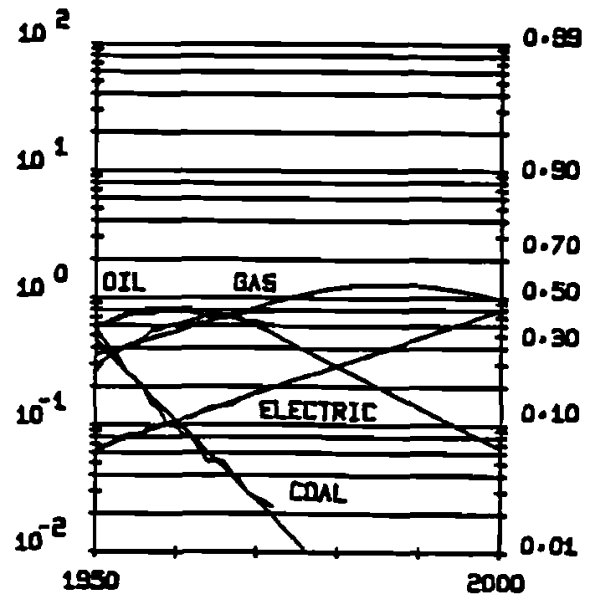

Reversing the previous reasoning, one can think that the various forms of energy compete for a certain sector. In this case, it is the householdcommercial sector. 
MIL. KNH

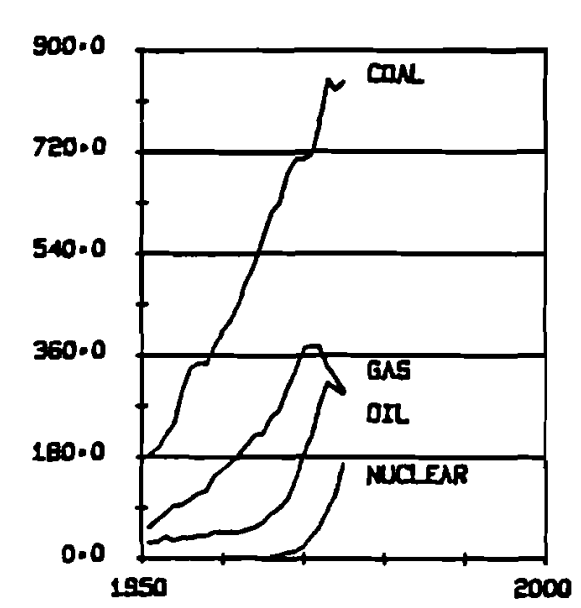

UILL. KWH

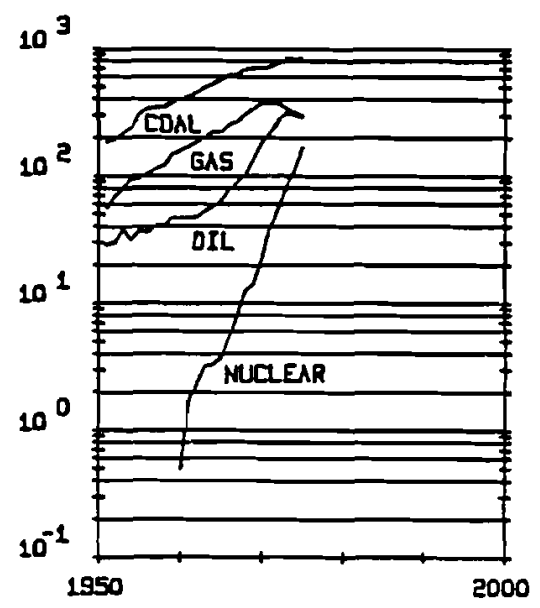

The electrical utility market is very important for primary energy producers. It is large, fairly homogeneous, highly technological, and rather profitable. Therefore, it is a good test-bed for observing the progress of new technologies. In these two figures, we plotted the evolution during the last 25 years of the production of electricity according to the various primary fuels, both in linear and semilog form.

The historical data on electricity generation according to primary energy fuels in millions of kilowatt hours $(\mathrm{kWh})$, as well as the data on primary energy consumption for electricity production in billions of British thermal units used later in this report, have been taken from the U.S. Bureau of the Census $(1975,1976,1977)$. The two data sets show implicitly the relative conversion efficiencies for electricity generation according to the various energy inputs used. 
USA - EECTRICITY BY PRIMARY INFUTS

$F /(1-F)$

FRACTION (F) FRACTION (F)
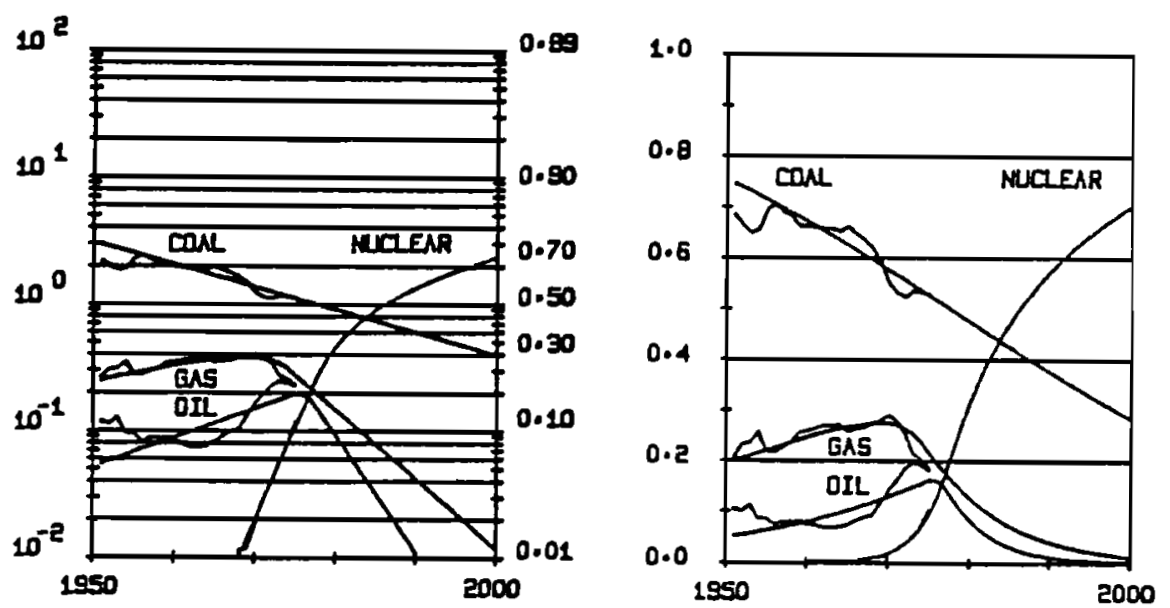

Electricity generated using coal, oil, or gas is shown here in a logistic representation. This is an indirect way of showing the competition of the various primary energies. 


\section{USA - PRIUARY IAPUTS TO ELETRICITY}

AIU TCE
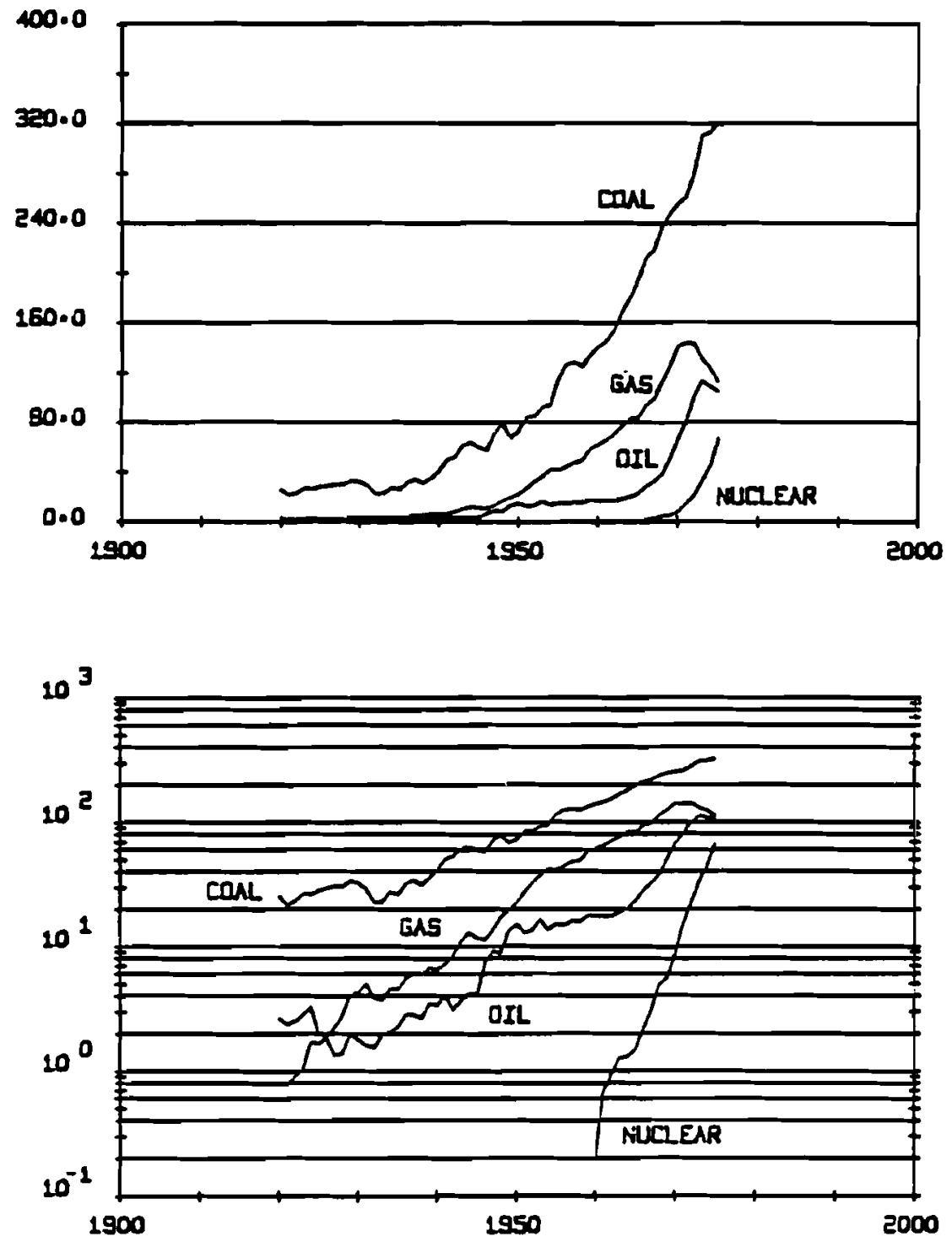
Here the competition is expressed more explicitly in terms of millions of tons of coal equivalent (tce) of different fuels entering the electricity market. It is clear that coal has been under constant attack by oil and gas, which have progressively eroded its position. A perturbation appears in the period from 1955 to 1970, showing an excessive consumption of gas with respect to oil. This may appear strange since during this period oil was "cheap and abundant." But in the United States, gas was still cheaper because of stringent price regulation. Oil recovers, however, and regains its position from 1973 to 1974 ! 
$f /(1-f)$

FRACTION (F)

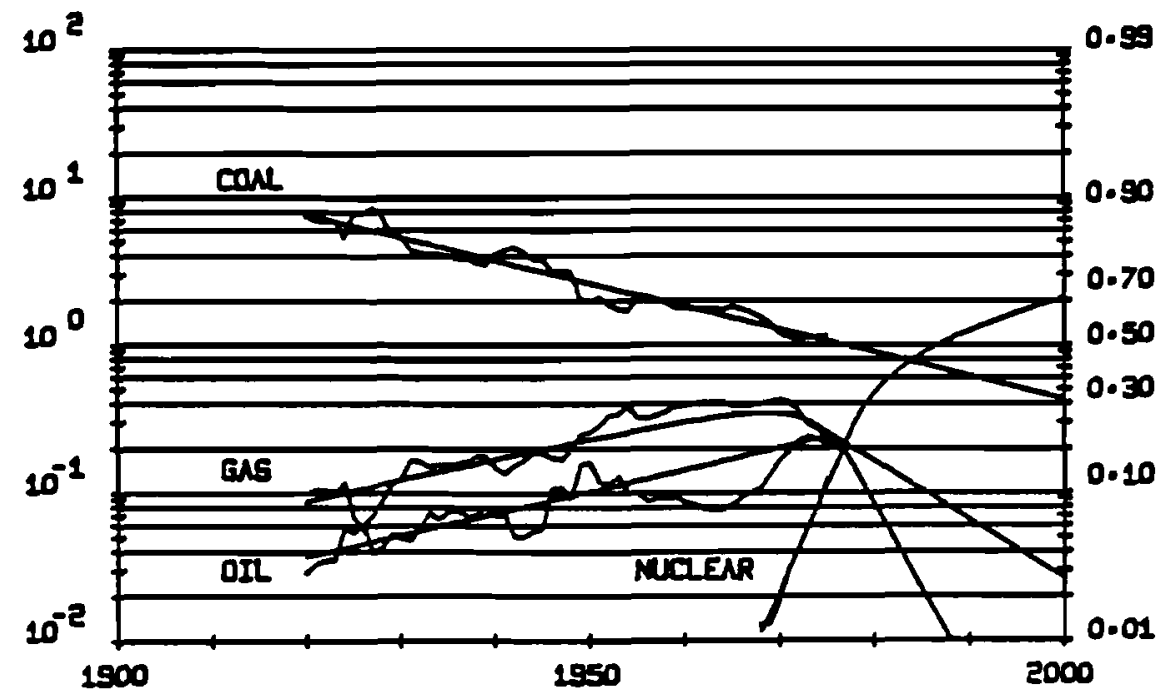

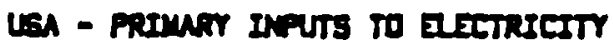

\section{PRACTION (F)}

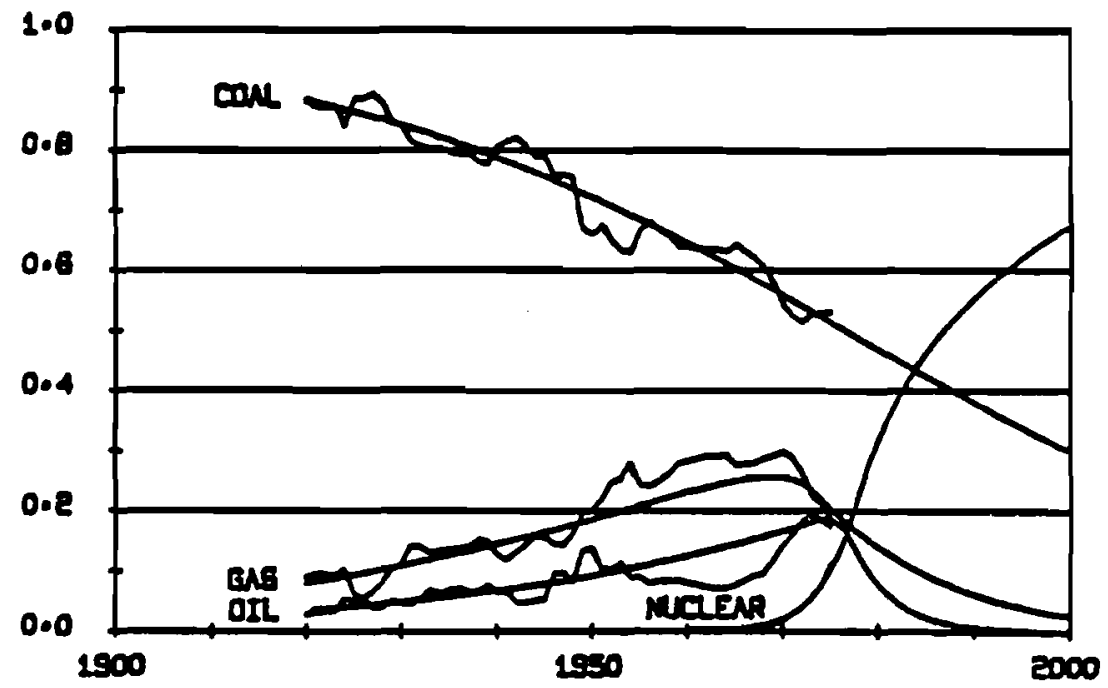


The substitution of different primary inputs in electricity generation is discontinuous when nuclear enters the market with a powerful drive and phases out oil and gas before the end of the century (facing page, top). Coal appears perfectly unperturbed and finally dictates the pace of introduction of nuclear from 1980 on. It is interesting, even if a little shocking, that this pace had been finally determined by the penetration rates of oil and gas in the twenties. Many problems surface from the expected structure of the system in the next 20 years. For example: What kind of peaking system will be provided? Will it be through medium-Btu gas from coal and gas turbines or through storage?

The lower figure on the facing page reports the same results but in linear terms in order to make it easy to interpret. Connected with the fast substitution of nuclear energy in the electricity market is the possibility of a kink in the nuclear penetration curve during the coming years, leading to lower market substitution and a smooth transition. 
LSA - PRTMRPY INPUTS TO EDETRICITY

$F /(1-f)$

FRRCTION (F)

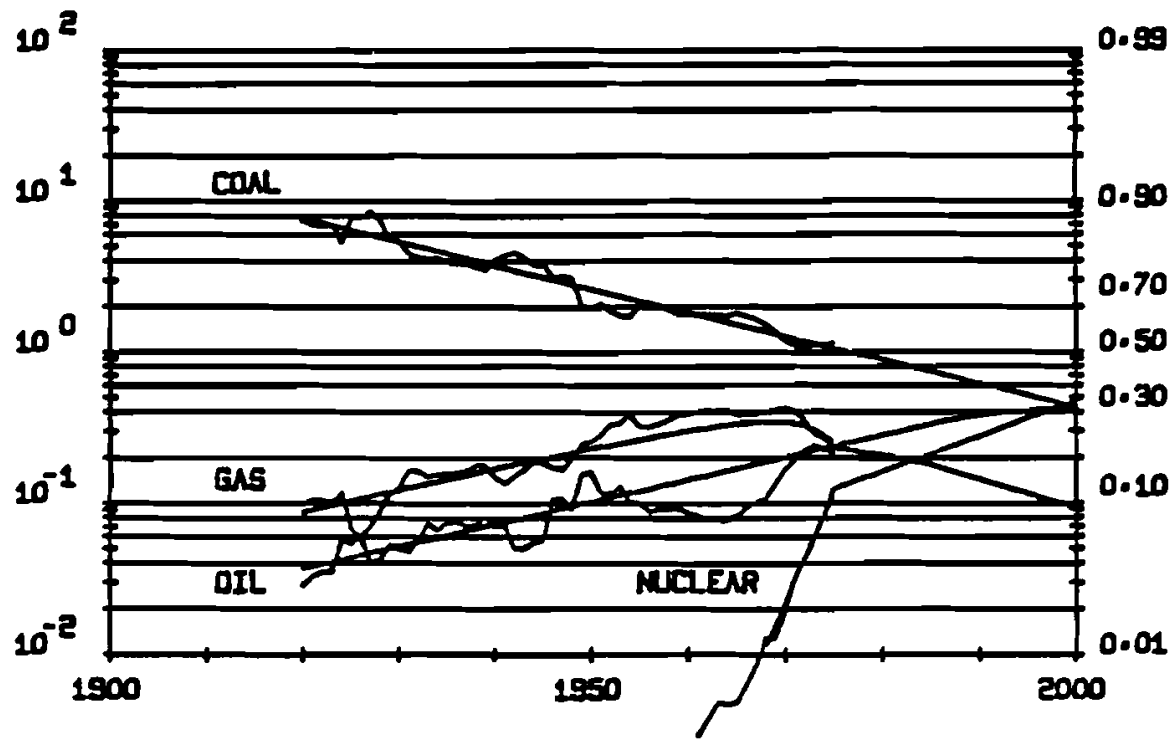


When the nuclear energy penetration of the market is plotted starting with a market share lower than the 1-percent share reached in 1967, no change of the substitution rates can be observed; in most other examples, nuclear energy and natural gas stabilize to a slower penetration rate once they take a few percent of the market (e.g., for nuclear energy see pages 31,33 , and 36 , and for natural gas see pages $33,36,63$, and 66). Assuming that this kink will occur before the end of this decade, we observe higher natural gas and oil shares, and coal remains unaffected. The nuclear share in the year 2000 is more than halved to about 30 percent. This slower penetration of nuclear energy has been determined by a scenario based on the nuclear share in 1976 and the expected share in 1990 calculated from the nuclear installed capacity under construction and the planned power plants ( $610 \mathrm{GW}(\mathrm{th})$; see page 41$)$, and the historical growth of the electricity market at 6.2 percent per year. The result is sensitive to the value for that historical growth. 


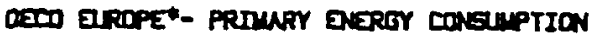

MIL. TEF

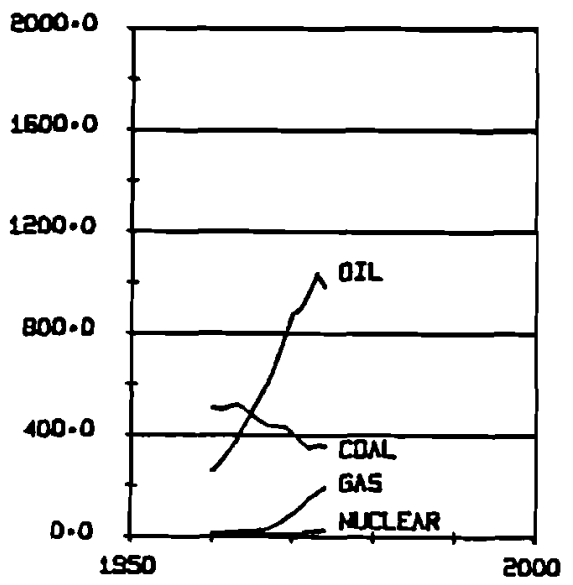

MILL. TLE

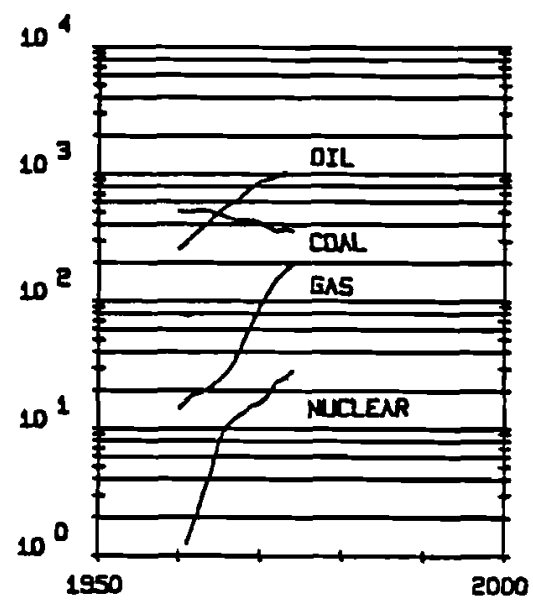

The data come from the OECD (1976). We made a logistic analysis for the European OECD states lumped together and for some of the states separately. The data base is relatively short, 15 years, but the curves appear very stable. The overall OECD case is presented here.

*Austria, Belgium, Luxemburg, Denmark, Finland, France, FRG, Greece, Iceland, Ireland, Italy, the Netherlands, Norway, Portugal, Spain, Sweden, Switzerland. 
DID EROPE - PRIART ENERTY SEESTITUIION
$f /(1-f)$
FRACTION (F)
FRACTIDN (F)
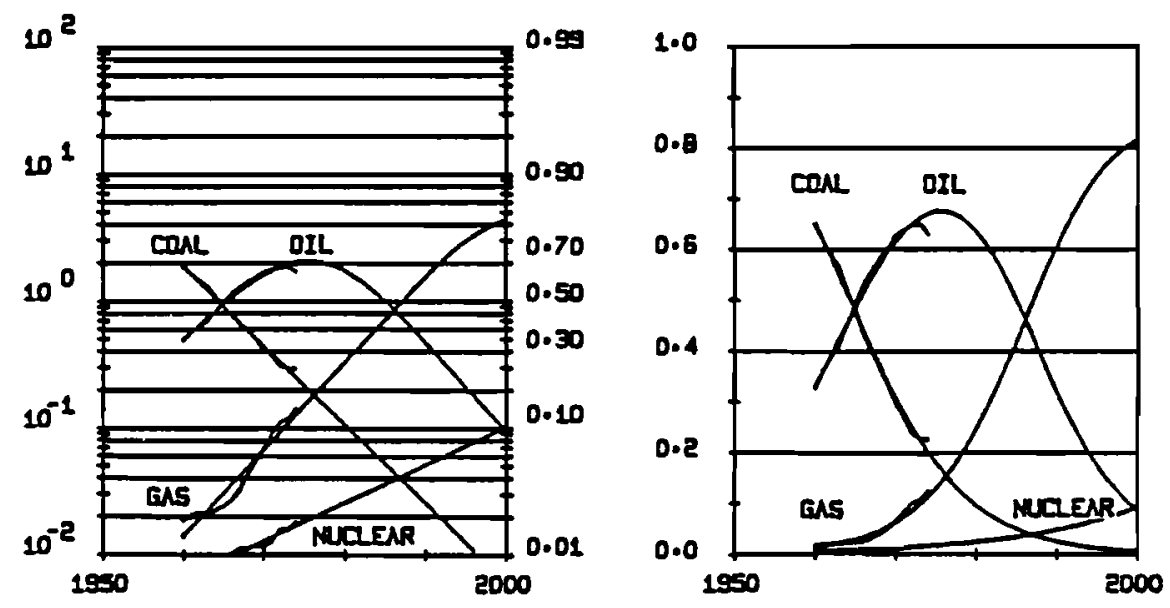

The logistic analysis for OECD is presented here in the log and linear form. Coal and oil behave very regularly. Natural gas has prolonged the start-up vagaries up to 10 percent of the market. The fact that it shows a penetration rate virtually identical to that of oil is a sign that tends to confirm the good quality of the projections. Nuclear has penetrated only to 2 percent; consequently, the projection is still somewhat uncertain. Any change in rate, however, would not change the projection that gas will become the next dominant primary energy source.

Two facts emerge; one is that natural gas, with a penetration rate much similar to that of oil, appears to be the primary source in the year 2000. It appears to drive oil to an impressively low level of 10 percent in that year. Second, the curve for nuclear seems quite regular, although the definition of the final substitution rate is still open owing to the current low level of penetration. With the present rate, nuclear would reach a somewhat unimpressive share of 10 percent of the market in the year 2000, leaving Europe completely dependent on hydrocarbons. SOLFUS has not been included as a scenario. It would possibly make nuclear saturate the market during the first half of the next century. 
ALSTRIA - PRIMART ENERGY CONSUNPTICN

UNL. TES

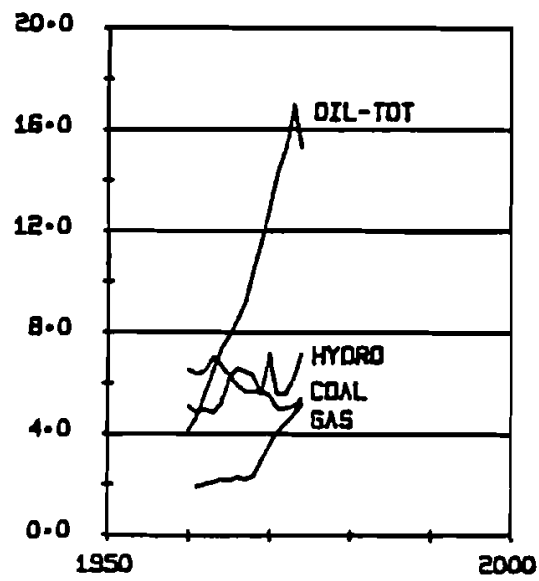

MIL. TCE

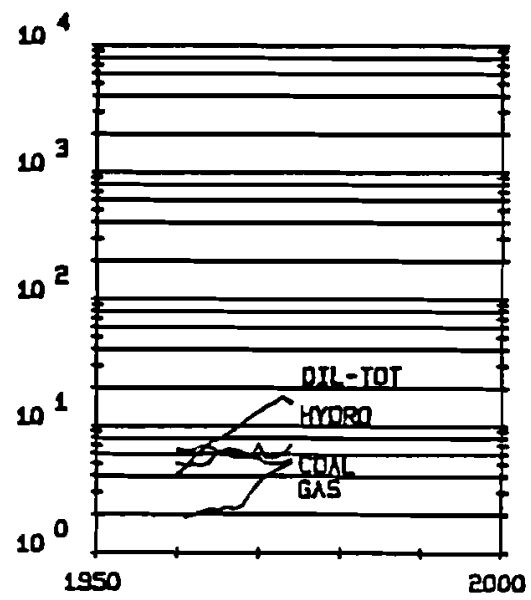

The primary energy consumption for Austria displays minimal dispersion except for rapid growth in oil consumption. Hydropower has been included in the set of primary energies because it is quite an important energy source for Austria. The market appears dominated by oil, with natural gas still low but increasing fast.

On the facing page, the data are presented in the log and linear logistic format. In the first row, no new sources are introduced. This may not have many consequences before the year 2000 because the time constant of the country appears to be so large (about 100 years). The situation with respect to nuclear is extremely confused. One power station was built but is not in operation owing to a referendum. No second power station is in sight, but nuclear electricity is being imported from neighboring countries.

The figures in the second row should then be considered as a sensitivity analysis indicating the potential influence of nuclear energy on the other primary sources. If we hypothesize a 4-percent penetration in the year 2000 , the medium-term effect would be a slight reduction of oil imports. Gas consumption would be affected only after 2020 . Only an improbable, very fast nuclear penetration could make Austria reasonably independent of oil in the next 30 years. 
AISTRTA - PRIURY ENDW SUSTITUTION
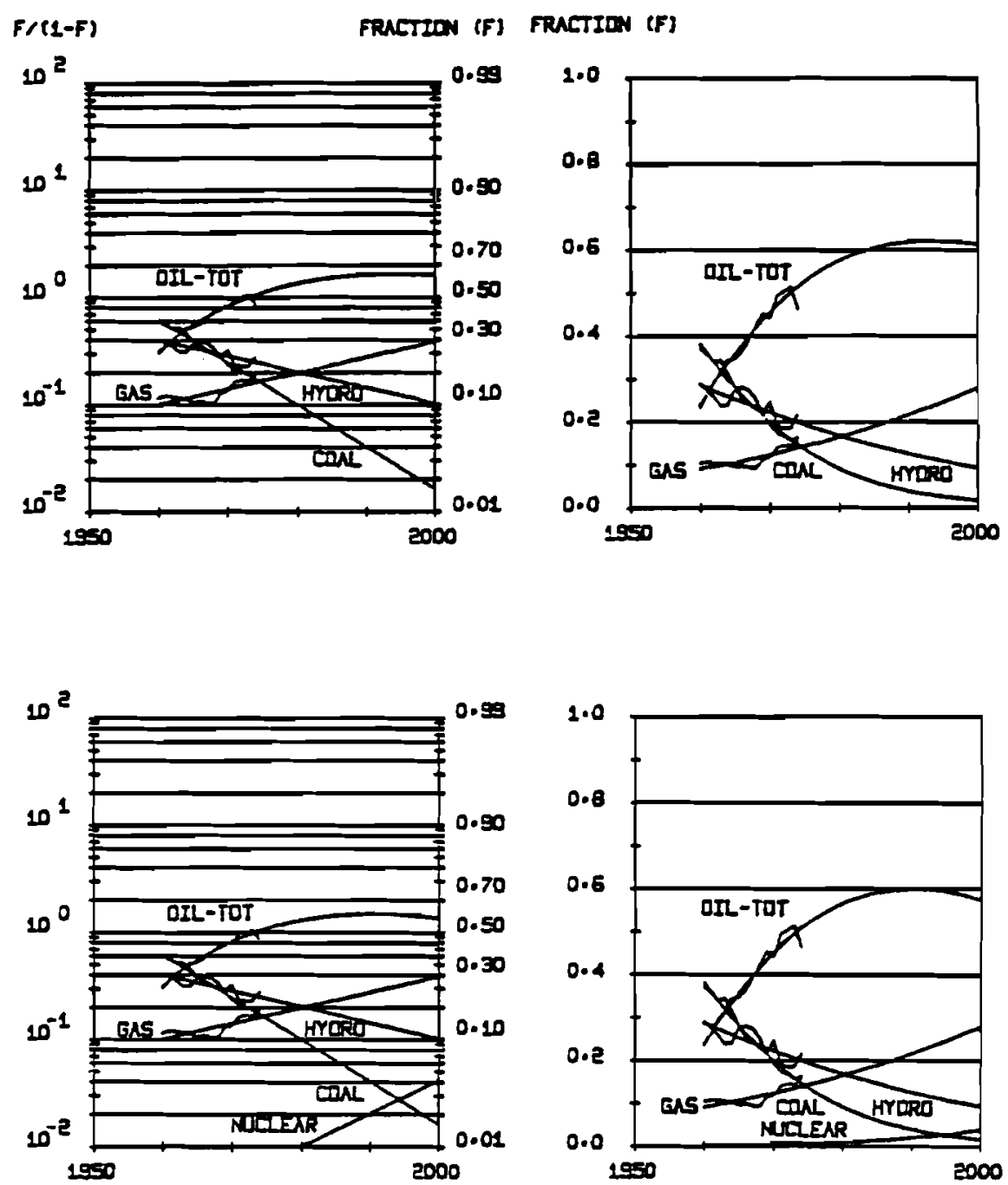


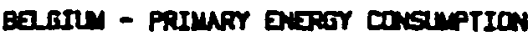

MIU. TOS

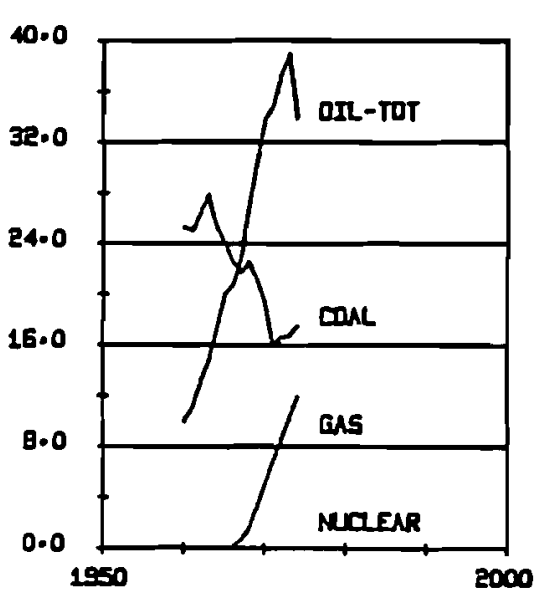

4ก1. TOE

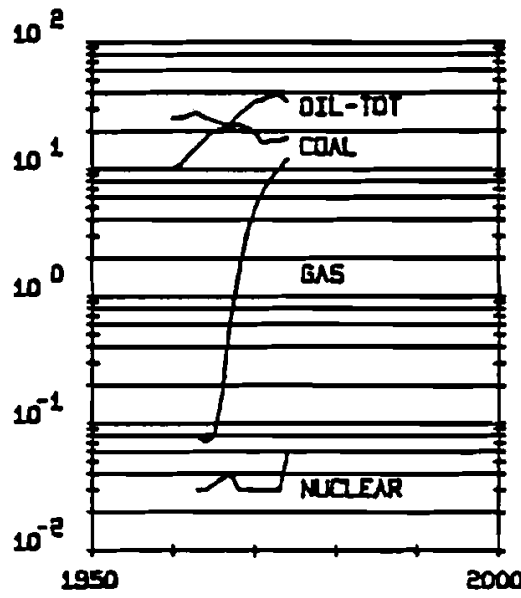

BATIN - PRIMNR ENaY SIBSTITUTION

$F /(1-F)$

FRACTION (F) FRACTION (F)
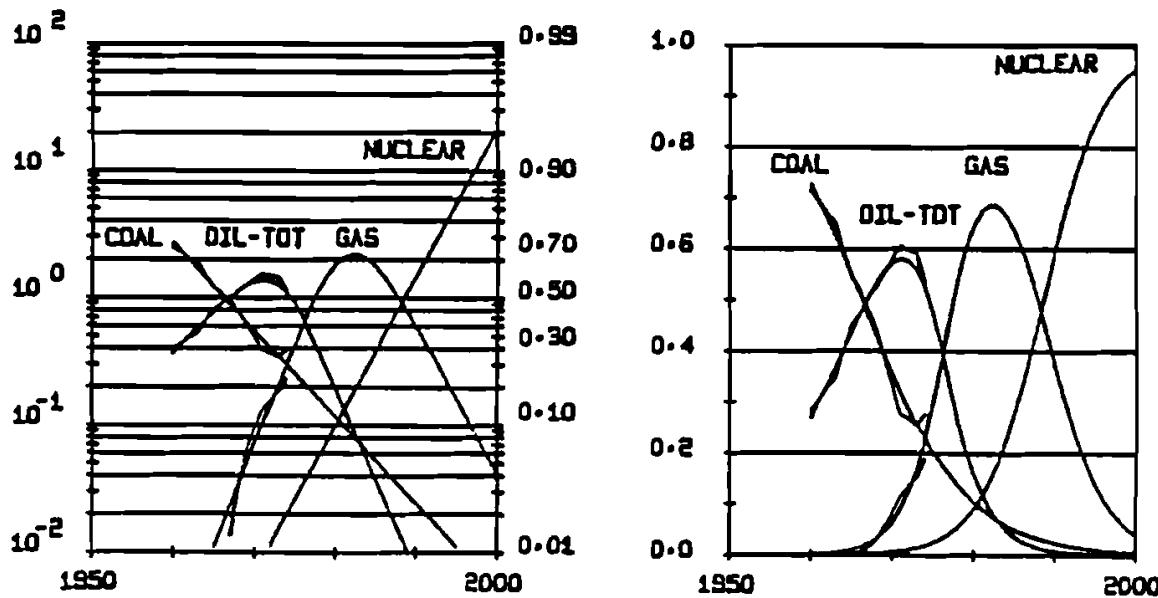
Without logistic analysis, the data on primary energy consumption in Belgium suggest that oil is the dominant primary energy, with no limits to its future (upper figure on the facing page). Coal is rapidly phasing out and gas is phasing in. Nuclear is barely perceptible (in 1974).

In the lower figure, logistic analysis reveals the hidden order. Although the data cover a short period of time, the good quality of the fit gives weight to the following considerations.

Coal seems to disappear around the year 2000 , which is more or less in line with the ideas in the country. Oil, including the trade balance in oil products, peaks around 1973 and seems to phase out in 1990. This prediction, which, by the way, repeats itself in a similar form for the Netherlands, the FRG, and the UK, is a bit hard to swallow on technical grounds. How will cars run in 1995? Will they use increasing amounts of methanol produced from coal and natural gas? This would in fact preserve their compatibility with gasoline, necessary at least for long-distance traveling. If coal is the primary source, a new curve may be required for underground coal gasification, i.e., for new coal. Electric, hydrogen- or methanol-electric, and pure hydrogen cars are in principle possible, but do not seem very probable in this time period.

We could also have overestimated the rate of penetration for gas. External interests prop up the penetration of a new technology at very high rates, usually until it has penetrated a few percent of the market. One could make the hypothesis that a particularly favorable environment, in this case the prior existence of an efficient distribution net for gas, and the spacial concentration of population, has prolonged this initial stage up to 10 percent. Yet, a change in the penetration rate from that point would only delay the disappearance of oil by a few years. A similar tampering with the rate of penetration of nuclear, which is still fairly hypothetical because of many lingering doubts, shows other possible small gains, but is not really decisive. So the problem is substantially left open. If we believe in the predictive capacity of our methodology, something fairly drastic will occur in the automotive field during the next 20 years, and the focal area will be in Belgium, the Netherlands, or the FRG. 
MUL. TEE

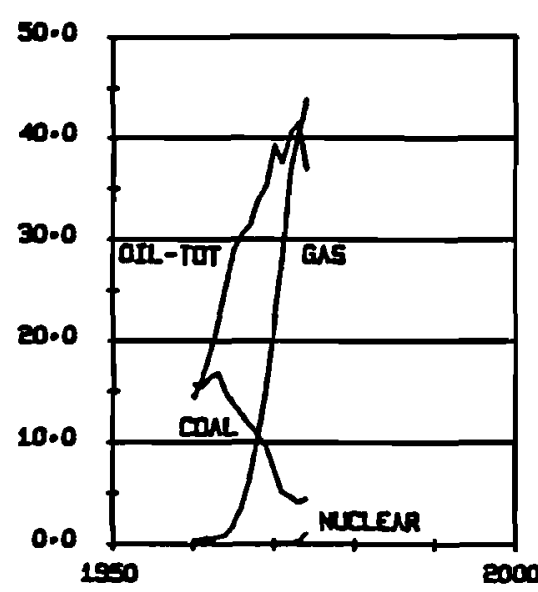

MII. TCE

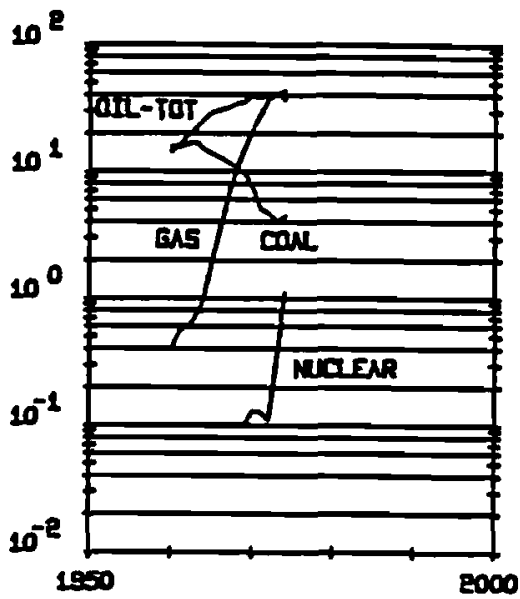

Primary energy consumption in the Netherlands is here reported by primary source, in linear and semilog form to stress the starting period. No particular tendency emerges; coal is phasing out and oil is phasing in. Gas made a very fast inroad after the discovery of the Gröningen field. Nuclear is just emerging. 
NETHERUNOS - PRIURT ENEROT SESTITUIIOA

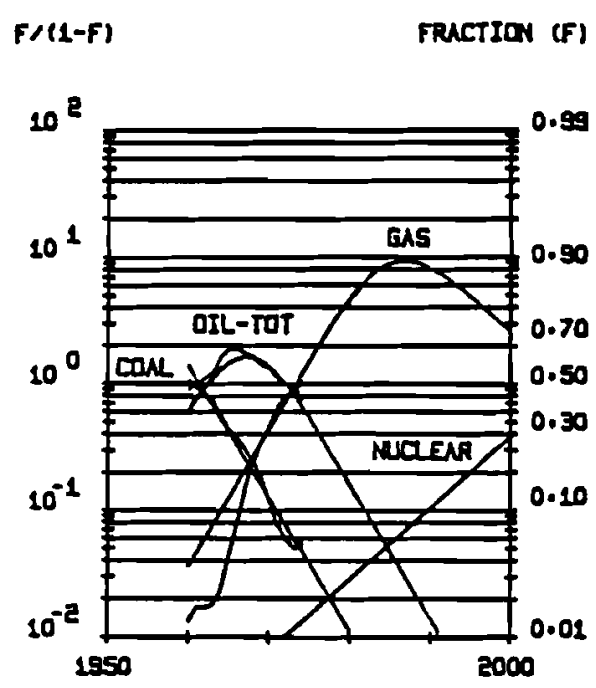

FRUCTION (F)

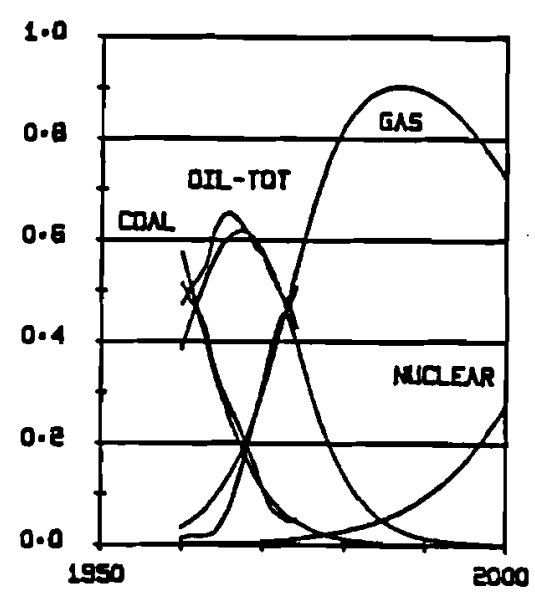

The logistic analysis shows here a quite precise structure. Coal is bound to disappear in 1980 and oil in 1990, opening the question about cars discussed already in the case of Belgium. The problem of nuclear is perfectly open and our scenario is pure guessing. It must be clear that if nuclear electricity is imported in spite of antinuclear opposition, nuclear should still be included in the energy budget. However, since natural gas has such a dominating role, the rate of introduction of nuclear energy will have little influence on the fate of oil. Thus, the car question is left open.

Seen in the light of our analysis, the Netherlands' alternatives appear to be natural gas or nuclear, and, thus, one understands better the importance of the debate about nuclear energy. 


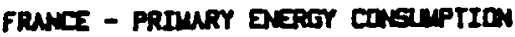

UIL. TCE

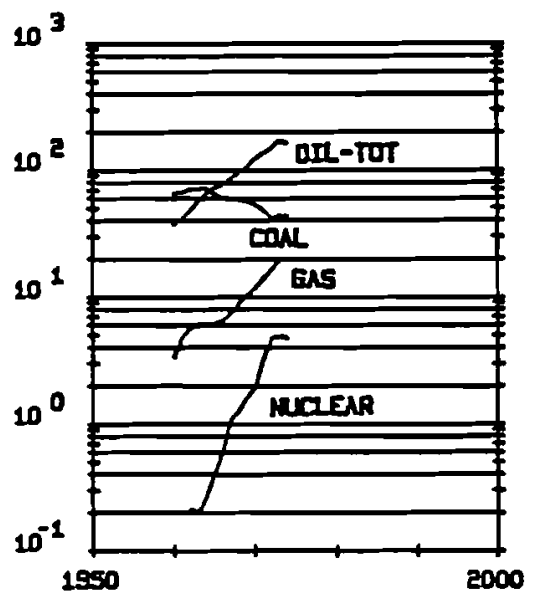

$F /(1-f)$

FRACTION (F)

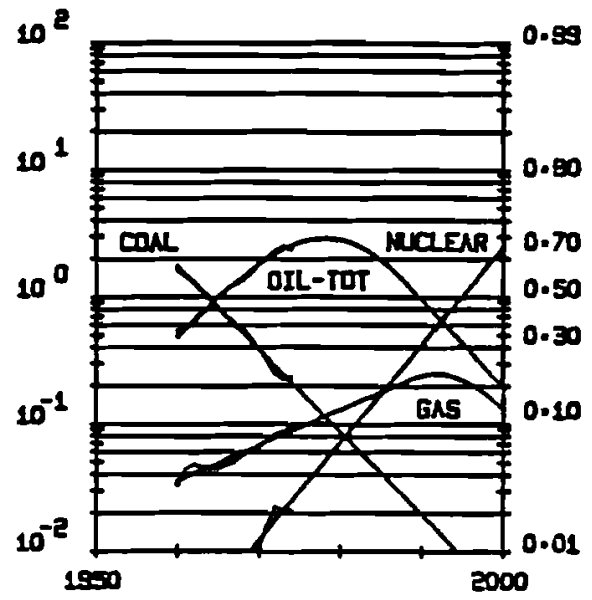

The primary energy substitution for France is repeated here using OECD data sources. The result is substantially the same as on page 33 , although different data and a shorter data base are used, which leads to minor discrepancies in the long run. For the nuclear scenario we estimated an 8-percent penetration in 1980, which comes from the fitting of the data, although the current market share is still below 2 percent. However, nuclear energy is growing fast in France and the situation should become clear in a few years. 
un. TCE

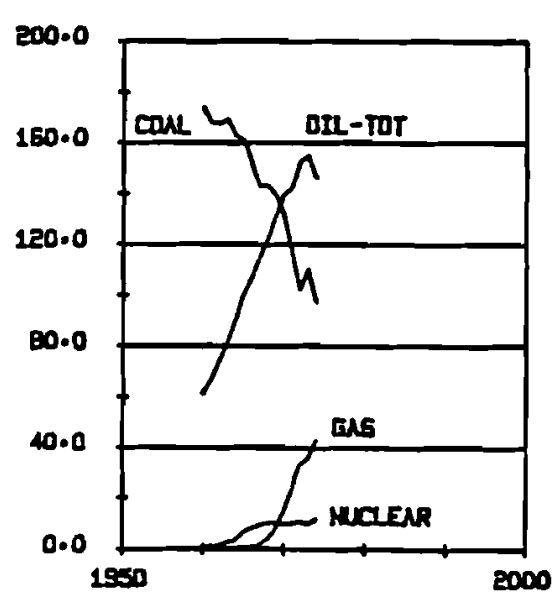

$F(1-F)$

FRnCTION (F)

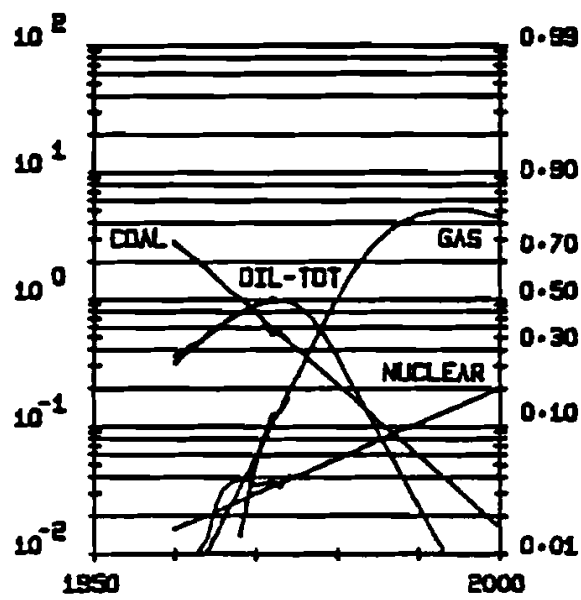

The primary energy substitution for the UK is repeated here using OECD data. In spite of some discrepancies with other data sources, the predictions differ only in relatively small details from those on page 36 . Even if nuclear should penetrate the market more rapidly, it would produce only a small dent in the dominance of gas during the next several decades. 
ITALY - PRIMARY ENJRG CONSIMPTION

MRL. TEE

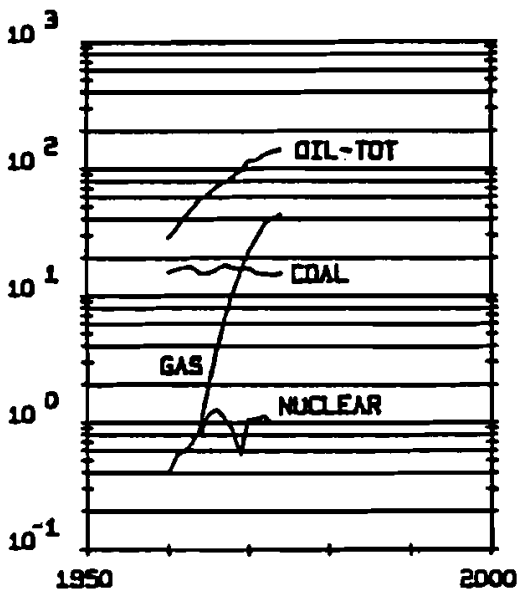

$F /(1-F)$

FRACTION (F)

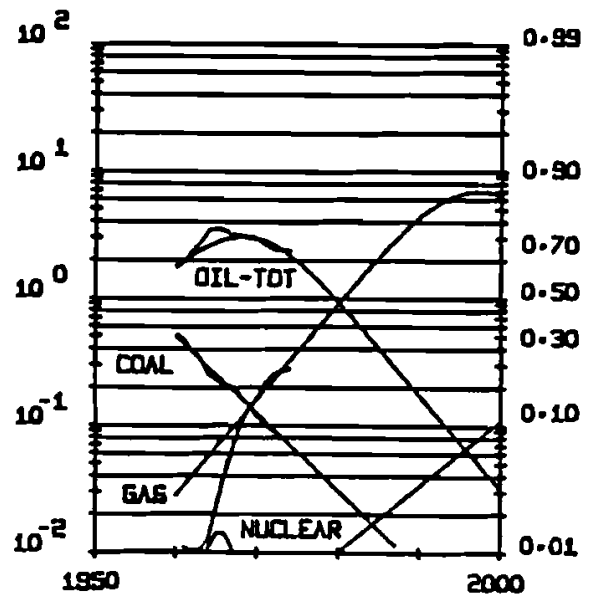

The primary energy consumption (left) and substitution (right) for Italy are shown here with a 15-year OECD data base. The penetration of nuclear energy (10 percent by the year 2000) is hypothetical and based on the assumption that Italy will not be very different in that respect from other European OECD countries.

The future appears very bright for gas to reach dominance in the next decade. Although this is supported by the efforts to link Italy with the Netherlands, the Soviet Union, and North Africa, via a pipeline under the Mediterranean, it is certainly beyond the rosiest plans of the gas industry. If we assume that gas growth was "forced" up to 10 percent and consequently fit the logistic with later data, and set nuclear penetration (improbably) as fast as gas, we reach a more acceptable but not very different conclusion. 


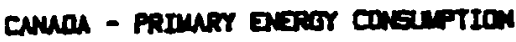

uIL. Tar

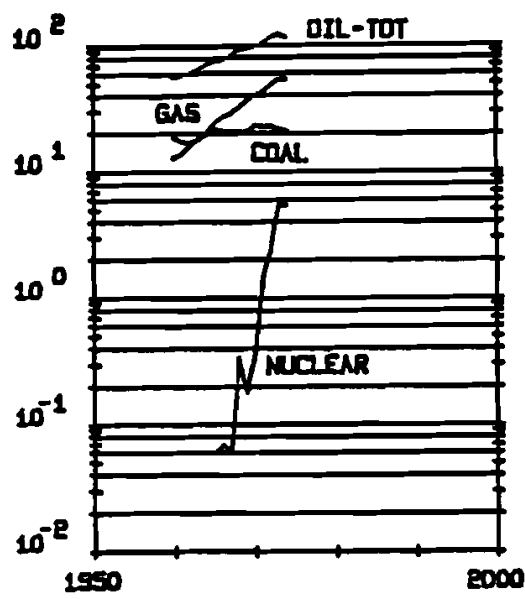

$F /(2-f)$

FRACTION (F)

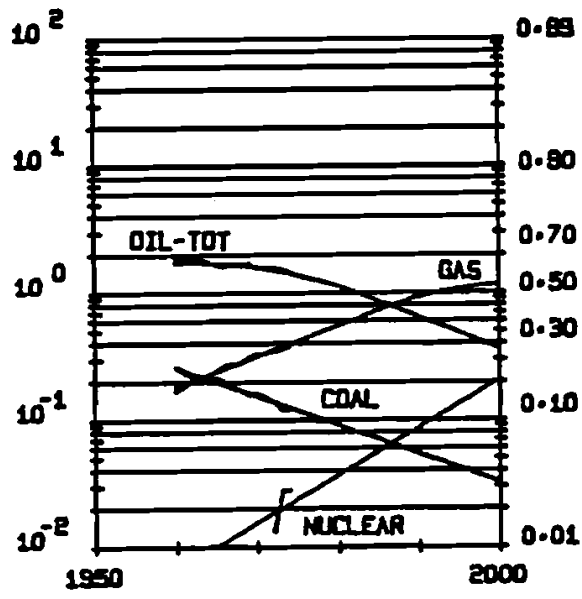

The primary energy consumption data for Canada do not show any particular pattern, except a very fast inroad of nuclear energy, although at a relatively low level. The logistic analysis reveals extremely smooth transitions, much similar to those of Austria, with time constants on the order of 70 to 80 years. In spite of Canadian devotion to nuclear energy, we drew a prudent scenario, assuming about 16-percent nuclear in the year 2000. As in most of the world, gas appears to peak and become dominant in the year 2000 . 
LAPAY - PRIMARY DIXEY CONEMPTION

Mill. TcE

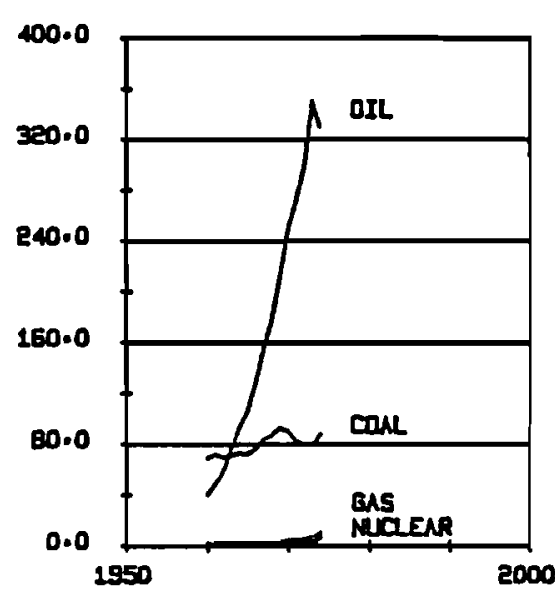

unt. Tre

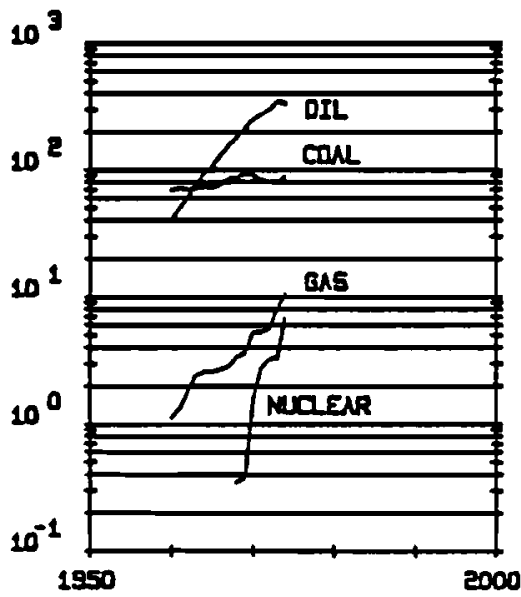

LPAN - PRTMRY घaRor sast ITUTINN

$f /(1-F)$

FRACTION (F) FRACTION (F)
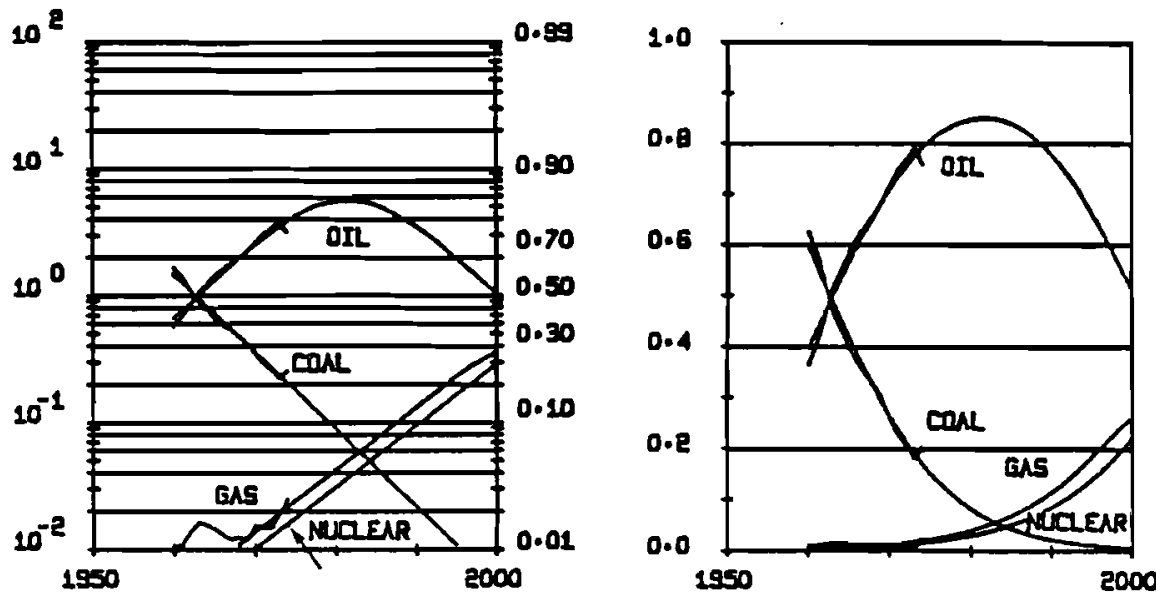
The primary energy consumption data for Japan are taken from the OECD and cover the period 1960 to 1974 for coal, oil, natural gas, and nuclear; they are all expressed in millions of tons of coal equivalent (tce). The oil data include consumption of crude oil and petrochemical products. Nuclear is just beginning. Today there are $20 \mathrm{GW}(\mathrm{th})$ of installed capacity (IAEA 1977), amounting to about 2 percent of primary equivalent.

In spite of Japan's unique situation as a country with very large, recently developed industry linked to an almost complete dependence on imports, the primary energy substitution shows nothing very unusual. Coal is being replaced by oil, a trend begun after World War II that appears to end in the nineties. The dependence on oil is fundamental, but only a little higher than that of France and similar to that of Italy. Oil starts to saturate now, as the equations could have predicted (using data before the oil crisis!). According to the equations, oil should be phased out around 2030, much later than for France or Italy.

Gas enters the scene somewhat late, at the end of the sixties, perhaps because it has to be imported using the complex technology of LNG. Perhaps for the same reason it does not seem to play the same central role as in Europe or the United States. According to the equations, it should peak around the year 2010, in consonance with the world peak.

Nuclear is fairly hypothetical, although we have tried to use the various forecasts prudently. The isolated point near gas (see arrow) indicates the actual situation. With nuclear penetration reaching 10 percent in the nineties, the rate coincides with that of other fuels. Nuclear would then become dominant during the first half of the next century, even if a new source is introduced around the year 2000 .

Today there are $20 \mathrm{GW}(\mathrm{th})$ of installed capacity (IAEA 1977), amounting in terms of primary equivalent to more than a 2-percent share. Additional plants with a total installed capacity of $27.6 \mathrm{GW}(\mathrm{th})$ are under construction and should be in commercial operation by 1982. Another 14.7 GW(th) are planned to be available by 1984 (IAEA 1977). Assuming that the long-term energy consumption growth prevails during the next decade and that the utilization factor is 75 percent, we project a nuclear share of about 7 percent by 1984. Our scenario of the long-term nuclear penetration rate assumes that licensing and political and construction problems will lead to delays. Thus, we predict a 7 -percent share 4 years later in 1988.

At the turn of the century, oil, gas, and nuclear appear to share the market equally, which implies an extraordinary advance in the technologies of transporting natural gas (or some derived products?) overseas and a virtual saturation of the electricity market by nuclear power stations. 


\section{DATA SOURCES}

Atomwirtschaft-Atomtechnik (1976) Die Entwicklung der deutschen Elektrizitätswirtschaft in den letzten $25 \mathrm{Jahren}$. Handelsblatt GmbH, Verlag für Wirtschaftsinformation, Düsselldorf.

FSR (1946) A Reappraisal of the Forest Situation, "Potential Requirements for Timber Products in the United States." Forest Service Report No. 2.

International Atomic Energy Agency $(1976,1977)$ Power Reactors in Member States. 1976, 1977 eds. Vienna.

Kernforschungsanlage Jülich (1977) Angewandte Systemanalyse. Nr. 1, Die Entwicklungsmöglichkeiten der Energiewirtschaft in der Bundesrepublik Deutschland, Untersuchung mit Hilfe eines Dynamischen Simulationsmodelles. Vol. 1, 2.

National Coal Association (1972) Bituminous Coal Facts 1972. Washington, D.C.

National Coal Association (1974) Coal Facts 1974-1975. Washington, D.C.

Organisation for Economic Co-operation and Development (1976) Energy Balances of OECD Countries 1960-1974. Paris.

Ormerod, R. (1976) Operational Research Executive of the National Coal Board, U.K., private communication.

Putnam, P.C. (1953) Energy in the Future. D. Van Nostrand Co., New York.

Reynolds, R.V., and A.H. Pierson (1942) Fuel Wood Used in the United States, 1630-1930. USDA Forest Service, Circular No. 641.

Rheinisch-Westfälisches Elektrizitätswerke (R.W.E.) (1978) Energieflußbild der BRD. Essen.

Sassin, W. (1977) Sekundärenergie - Heute und Morgen, in, Großtechnische Energienutzung und menschlicher Lebensraum. Technical University of Vienna and Intemational Institute for Applied Systems Analysis, Laxenburg, Austria.

Schilling, H.D., and R. Hildebrandt (1977) Primärenergie-Elektrische Energie, Die Entwicklung des Verbrauchs an Primärenergieträgern und an Elektrischer Energie in der Welt, in den USA und in Deutschland seit 1860 bzw. 1925. Verlag Glückauf, Essen.

Schurr, S.H., B.C. Netschert, V.F. Eliasberg, J. Lerner, and H. Landsberg (1960) Energy in the American Economy 1850-1975, An Economic Study of its History and Prospects. Published for Resources for the Future, Inc. Johns Hopkins University Press, Baltimore.

UK Department of Energy $(1976,1977)$ Digest of United Kingdom Energy Statistics 1976, 1977. Government Statistical Service. Her Majesty's Stationery Office, London.

United Nations (1976) World Energy Supplies 1950-1975. New York.

United Nations (1977) World Energy Supplies 1971-1975, New York.

U.S. Bureau of the Census $(1975,1976,1977)$ Statistical Abstract of the United States: 1975, 1976, 1977 (96th, 97th, 98th eds.). Washington, D.C.

U.S. Bureau of the Census (1975a) Historical Statistics of the United States, Colonial Times to 1970, Parts 1 and 2. Washington, D.C.

U.S. Department of Agriculture (1958) Timber Resources for America's Future. Forest Service Report No. 14. 
Weitsch, A. (1976) Département de Physique des Particules Elémentaires. Commissariat à l'Energie Atomique, France (private communication).

\section{REFERENCES}

Bergson, J. (1944) Application of the Logistic Function to Bio-Assay. Journal of the American Statistical Association 39:357-365.

Emmens, C.W. (1941) The Dose-Response Relation for Certain Principles of the Pituitary Gland, and of the Serum and Urine of Pregnancy. Journal of Endocrinology $2: 194-225$.

Fisher, J.C., and R.H. Pry (1970) A Simple Substitution Model of Technological Change. Report 70-C-215, General Electric Company, Research and Development Center, Schenectady, N.Y., Technical Information Series; see also Technological Forecasting and Social Change 3(1971):75-88.

Griliches, Z. (1957) Hybrid Corn: An Exploration in the Economics of Technical Change. Econometrica 25:501-522.

Mansfield, E. (1961) Technical Change and the Rate of Imitation. Econometrica 29(4).

Marchetti, C., N. Nakicenovic, V. Peterka, and F. Fleck (1978) The Dynamics of Energy Systems and the Logistic Substitution Model. Report prepared for the Volkswagenwerk Foundation. AR-78-1 A,B,C. International Institute for Applied Systems Analysis, Laxenburg, Austria.

Nakicenovic, N. (1979) Software Package for the Logistic Substitution Model. RR-79-12. International Institute for Applied Systems Analysis, Laxenburg, Austria.

Pearl, R. (1924) Studies in Human Biology. Williams and Wilkins Co., Baltimore.

Pearl, R. (1925) The Biology of Population Growth. Alfred A. Knopf, Inc., New York.

Peterka, V. (1977) Macrodynamics of Technological Change: Market Penetration by New Technologies. RR-77-22. International Institute for Applied Systems Analysis, Laxenburg, Austria.

Pry, R.H. (1973) Forecasting the Diffusion of Technology. Report 73CRD220. General Electric Company, Corporate Research and Development, Schenectady, N.Y., Technical Information Series.

Richards, F.J. (1959) A Flexible Growth Function for Empirical Use. Journal of Experimental Botany 10(1959):290-300.

Robertson, T.B. (1923) The Chemical Basis of Growth and Senescence. J.P. Lippincott, Philadelphia.

Verhulst (1838) Corr. Math, et Phys, A. Quetklet, t.x, pp. 113-121.

Verhulst (1845) Nonv. Mem. de l'Acad. Roy. des Soc. et Belles-Lett. de Bruxelles, t. 18 , pp. $1-38$.

Verhulst (1847) Nonv. Mem. de l'Acad. Roy. des Soc. et Belles-Lett. de Bruxelles, $t$. 20 , pp. $1-32$.

Wilson, E.B., and J. Worcester (1942) The Determination of L.D. 50 and its Sampling Error in Bio-Assay, Proceedings of the National Academy of Sciences 29:79-85. 



\section{THE AUTHORS}

Cesare Marchetti joined IIASA's Energy Group in January 1974 and works on analysis and synthesis of energy systems. He was formerly Head of the Materials Division of the European Community Research Center.

Dr. Marchetti received his education in physics at the University of Pisa and at the Scuola Normale in Pisa.

He worked on the technology of heavy water separation at CISE (Milan) and DNEA (Buenos Aires), and on applied surface physics at the Battelle Institute (Geneva). He was head of the Physical Chemistry Division of AGIP Nucleare (Milan) and was appointed to various posts in the European Community Research Center.

Dr. Marchetti is member of various professional societies and an editor of the International Journal of Hydrogen Energy and Technological Forecasting and Social Change. In 1977 he received an Honorary Degree in Science from the University of Strathclyde, Glasgow, Scotland.

Nebojsa Nakicenovic joined IIASA's Program on Energy Systems in 1973. He was formerly with the Nuclear Research Center, Karlsruhe, FRG, working in the field of nuclear materials accountability. He received a degree in economics from Princeton University in 1971, where he worked as a research assistant in the field of game theory. He is now working toward a doctoral degree at the University of Vienna.

Mr. Nakicenovic's broader interests are in the fields of econometrics, game theory, global modeling, technological and social change, and information and data processing. 


\section{RELATED IIASA PUBLICATIONS}

RR-77-21 Software Package for Economic Modelling, by M. $\$ \mathbf{1 0 . 0 0 , A S 1 2 0}$ Norman.

RR-77-24 Food and Energy Choices for India: A Model for

$\$ 5.00$, AS60

Energy Planning with Endogenous Demand, by K.S Parikh and T.N. Srinivasan.

RR-78-2 The Bratsk-llimsk Territorial Production Complex: A Field Study Report, H. Knop and A. Straszak, eds.

RR-78-12 A Review of Energy Models No. 4 - July 1978. J.-M. \$6.00, AS70 Beaujean and J.-P. Charpentier, eds.

RR-78-17 MEDEE 2: A Model for Long-Term Energy Demand \$6.00, AS70 Evaluation, by $B$. Lapillonne.

RR-79-12 Software Package for the Logistic Substitution Model, \$7.00, AS85 by $\mathrm{N}$. Nakicenovic

CP-77-2 Methods of Systems Analysis for Long-Term Energy \$5.00, AS60 Development, Yu.D. Kononov, ed.

CP-77-5 Medium-Term Aspects of a Coal Revival: Two Case Studies. Report of the IIASA Coal Task Force, W. $\$ 8.50$, AS100 Sassin, F. Hoffmann, and M. Sadnicki, eds. 